\title{
RAZONES PARA NO CREER \\ EN LA ACTUAL TEORÍA (ILUSIONISTA) \\ DE LA ARGUMENTACIÓN
}

\section{Papel que tales teorizaciones cumplen como más nueva ideología de legitimación con respecto, especialmente, al discurso jurídico profesional}

\author{
(Observaciones sobre la falaciocidad de ellas como descripción \\ del pensamiento judicial y también acerca de su inocuidad \\ como propuesta práctica para este mismo) *
}

Enrique P. Haba

Universidad de Costa Rica

RESUMEN. Las teorías dominantes («estándar») sobre la argumentación jurídica pecan no tanto por buena parte de cuanto dicen..., jsino sobre todo por lo que no dicen! Son teorizaciones pseudodescriptivas - basadas en unas «intellectualist assumptions»—con respecto a los razonamientos jurídicos. Así ellas conducen a apartar la vista de los decisivos ingredientes de anti-racionalidad, señaladamente las falacias típicas del «Síndrome normativista», con base en los cuales se arman muchos de esos discursos en la práctica. Por lo demás, dichas concepciones fijan la atención simplemente en ciertos aspectos semánticos de la discursividad jurídica, haciendo abstracción de sus dimensiones pragmáticas. La Teoría "estándar» de la Argumentación resulta especialmente apta para ser asumida como ideología profesional («storytelling») de los operadores del Derecho positivo, es la más reciente: sus embellecimientos teoréticos (una "cirugía estética» frente a los razonamientos judiciales normales) y sus cómodos silencios (ante el Síndrome normativista y las consecuencias prácticas) legitiman los modus operandi tradicionales de esos operadores. Lo que aquí está en discusión no es si los juristas argumentan, sino cómo estas argumentaciones son de veras.

Palabras clave: pensamiento jurídico, Teoría («estándar») de la Argumentación, «síndrome normativista», ideología profesional.

ABSTRACT. Theory of Legal Argumentation -in its "standard» version - sins mainly, not by everything that their authors say, but essentially by what they do not say! Anyway, these theorizations are but pseudo-descriptions of legal reasoning —-based on some «intellectualist assumptions»for they look away from a net of current typical fallacies (the «normativist Syndrome») on which much of legal discourses are built upon in practice. The "standard» view about legal argumentation disguises such antirational ingredients. Moreover, it habitually concentrates only on certain semantic issues of legal discourses, but it doesn't pay attention to their pragmatics -i. e., the very practical consequences of any argument in different social and individual contexts-. Indeed,

* Fecha de recepción: 9 de mayo de 2011. Fecha de aceptación: 13 de mayo de 2011. 
those theories offer a professional ideology (storytelling) for lawyers, since their theoretical embellishments (something like a «plastic surgery» with Regard to actual judicial reasoning) and, in addition, their convenient silences provide a comfortable legitimization for the traditional modus operandi of legal thought. Here is not under discussion whether or not jurists argue, but the question is how do they really make that.

Keywords: legal thought, «standard» Theory of Argumentation, the «normativist syndrome», professional ideology. 
«La facultad de pensar idealmente constituye la ventaja peculiar del jurista teórico, y ella consiste en la facultad de desligarse, en el pensar jurídico, de todos aquellos presupuestos que atañen a la realización práctica de los problemas».

JHERING

«When one realises the non-rational character of most social behaviour, they (people) are apt to regard one as very wicked, as if one wishes it to be so. Not al all: one only wishes human beings were more rational, or at least more reasonable. They could well afford to be. But it is silly, and apt to be dangerous to the best causes in the world, to take your illusions for things as they are. That is all».

A. L. RowsE

«La “reconstrucción” parece más bien una cirugía estética».

C. COURTIS

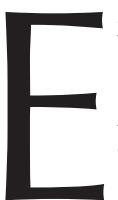

n la actualidad se viene imponiendo como visión bastante popular en el seno de la profesión jurídica la idea de que los razonamientos de esa disciplina ponen en ejercicio una racionalidad - $\mathrm{O}$ «razonabilidad»- bien específica, esencialmente argumentativa. Pues bien, si no se me toma demasiado a mal atreverme a caricaturizar un poco — sólo para anticipar lo más gráficamente posible por dónde corre el fondo mismo del asunto- en qué consiste básicamente tal perspectiva teorética, me atrevería a decir que ella viene a ser algo así como destilar unos programas dirigidos a que los gatos ladren bien o que los perros maúllen afinadamente. A lo largo del examen que presentaré aquí, habrá oportunidad de poner sobre el tapete las razones (propiamente) por las cuales tal símil es, si no me equivoco, apenas levemente exagerado.

Esta nueva ideología de legitimación para las formas con que el gremio de los juristas desempeña sus discursos propios, señaladamente en los tribunales, ha venido tomando el lugar que antes se le adjudicaba a la forma silogística para garantizar - supuestamente- el rigor del razonamiento en las sentencias. Si bien en la Teoría General del Derecho había sido abundantemente demostrado, al menos desde finales del siglo XIX, que la «seguridad» de tales silogismos es una ficción, dada la contingencia en las maneras de obtener el contenido de sus premisas, empero tal ideología no podía ser dejada simplemente de lado sin afectar la credibilidad de las resoluciones judiciales. Había que seguir aferrándose a ella, nolens volens, mientras no se tuviera a mano en reemplazo otra teorización capaz de cumplir funciones de legitimación similares, esto es, justificar la credulidad en que esas resoluciones son el producto de unas inferencias objetivamente «racionales». 
En años recientes se encontró por fin un sustituto ideológico viable, vale decir, lo bastante creíble a primera vista como para alcanzar suficiente difusión en satisfacer esas funciones ideológicas: la «racionalidad» de los razonamientos jurídico-profesionales en general, se presenta ahora como asegurada en virtud de su carácter argumentativo. Sin perjuicio, eso sí, de mantener las formas tradicionales de esos razonamientos, esto es, simplemente re-conociéndolas como plenamente legítimas tal como han sido y siguen siendo. Cambia así la forma teorética de ver -intercambio de argumentos (discurso «dialógico»), en vez de silogismo (discurso «monológico») ${ }^{1}$ — cómo se constituyen las fundamentaciones judiciales, pero sin necesidad de cambiar las vías de pensamiento en sí mismas usadas tradicionalmente para desempeñar tales discursos. Más aún: estos mismos, ;tal como son!, hasta llegan a encomiarse al punto tal de promocionarlas a título del mejor modelo para los razonamientos de la «Razón práctica» en general (ética, política, etc.).

Desde luego, las visiones «argumentativistas» sobre el razonamiento jurídico son una caracterización señaladamente menos simplista que la del «silogismo judicial». Así es cómo, al fin de cuentas, las ideas más difundidas de la nueva orientación —-su teoría «estándar» (infra, $\mathbb{S} 2$ ) — vienen a ser todavía mucho mas engañadoras que aquello del silogismo judicial. Cuanto ellas disimulan resulta menos patente a primera vista, por venir «mechado» con observaciones en donde se ponen de manifiesto unos aspectos que efectivamente pueden darse en las argumentaciones jurídicas. Como toda ideología, ella se hace creíble justamente por contener también referencias a unos aspectos empíricos perceptibles a primera vista. Solo que, mediante el relato ideológico (storytelling) ${ }^{2}$, esos aspectos se exhiben descontextualizados - los estudios «argumentativistas» hacen abstracción del Sindrome normativista (infra, $\mathbb{3}$ ) y de la pragmática discursiva - y por cierto muy hipostasiados —esa «racionalidad» o «razonabilidad» general atribuida a los operadores jurídicos-. Por lo demás, algunas de esas teorizaciones llegan hasta a ser singularmente sofisticadas: así unos disfraces logicistas como los pergeñados por R. ALEXY para presentar los procedimientos de «ponderación» de principios constitucionales; este autor se vale de ciertos artificios formulistas que dejan escondido - bajo esa maraña de esquematizaciones lógico-matemáticas, supuestamente «objetivas»— el carácter básicamente ideológico-voluntarista que tienen las derivaciones conceptuales efectuadas mediante tales razonamientos ${ }^{3}$.

${ }^{1}$ Cfr. E. PiacenZA, Teoría de la argumentación. Lógica y no-monotonía, Memorias del ciclo de conferencias «XXX Aniversario del Centro de Estudios Filosóficos "Adolfo García Díaz”», Maracaibo, 1998.

2 Cfr. C. SALmON, Storytelling. La máquina de fabricar historias y formatear las mentes (trad. I. Bértolo), Barcelona y vid. infra, $\$ 9,2008$.

3 Cfr. J. A. GARCía AMADO, «El juicio de ponderación y sus partes. Una crítica», en GARCía Amado, El Derecho y sus circunstancias. Nuevos ensayos de filosofía jurídica, Bogotá, 2010, 207-245. Pero cabe reconocer que aun esas logificaciones de ALEXY resultan algo así como un juego de niños, todavía no demasiado lejano con respecto a las «travesusas» de los operadores jurídicos reales, si aquéllas venimos a compararlas con unos extremos tan infinitamente ajenos al pensamiento de estos mismos como esa vía láctea de axiomatizaciones que conforman el divertimento extraempírico mayor propuesto por L. FERRAJOLI para entretener a profesores de Teoría del Derecho [cfr., de este autor, Principia iuris. Teoria del diritto e della democrazia, Roma, 2007, esp. su t. III]. No sólo es imposible de hecho que los juristas prácticos se consagren a semejantes escolasticismos, sino que mediante estos últimos se esfuman aquellas cuestiones en debate que deciden verdaderamente cuáles son las respuestas efectivas en las disputas jurídicas reales; por lo demás, a cualquier conclusión jurídica viable se llega igualmente sin necesidad alguna de someterla a otra «cámara de torturas» (RADBRUCH) más, en este caso 
Así y todo, cabe reconocer que esas teorías «estándar» no dejan de hacer referencia, como ya dije, a ciertos aspectos que efectivamente suelen formar parte de los discursos jurídicos, ya sea dejándolo ellas señalado de manera llana (el mejor ejemplo son los correspondientes estudios de PERELMAN) o aun bajo unas conceptuaciones bastante artificiosas (p. ej., ALEXY). Mas ello no quita que, al fin de cuentas, los énfasis principales de los planteamientos efectuados en tales estudios vengan a sustentar la misma disimulación de fondo propiciada por la tradicional tesis del silogismo. Tanto en estas modernas visiones «argumentativistas» como en la clásica, en ambas se exhiben cual si fueran esencialmente «racionales», o ahora llamándolos «razonables», unos desempeños discursivos que, analizados sin cohonestarles sus eufemismos disimulantes ni «hacer la vista gorda» frente a las falacias de razonamiento muy corrientes allí, en la práctica son producto de ciertos hábitos de pensamiento engañadores (una variedad de «celadas» lingüísticas) y están sujetos a múltiples condicionamientos fáctico-sociales (limitaciones materiales, grupos de presión, intereses personales de los propios operadores). Los estudios que responden a las teorías dominantes sobre la argumentación jurídica, no menos que la visión silogística, suelen hacer abstracción de todo eso.

Señalado de la manera más sintética: dichas teorías pecan no tanto por todas las cosas que dicen... isino sobre todo por lo que no dicen! Son unas teorizaciones pseudo-descriptivas con respecto a los razonamientos jurídicos. De hecho, ellas conducen a apartar la vista (storytelling, ideología profesional) de los decisivos factores de no-racionalidad con base en los cuales a menudo son configurados esos discursos en la práctica, por parte de sus operadores normales. Lo que aquí será sometido a discusión no es si los juristas efectúan unas argumentaciones, hecho indubitable, sino cómo ellas son en la práctica misma del Derecho. Para explicarme, seguiré el plan de exposición siguiente:

1. Visión general:

I. TEORÍA «ESTÁNDAR» VS. «SÍNDROME NORMATIVISTA»: 2. Rasgos fundamentales de la concepción ilusionista sobre las argumentaciones que efectúan los juristas: su teoría «estándar». 3. El Síndrome normativista.

II. CARÁCTER SUPRAEMPÍRICO DE LAS TEORÍAS ARGUMENTATIVO-«RAZONABILISTAS»: 4. La apología subrepticia. 5. Incertidumbre y manipulabilidad de lo que es llamado «razonable». 6. Esas teorías sobre la argumentación jurídica constituyen sobre todo una modalidad de prédica, no son una explicación empírico-científica.

III. «RACIONALIDAD» COMO EXPEDIENTE PARA TEORIZACIONES ESCAPISTAS: 7. «Racionalidad» o «razonabilidad» fantasiosas, en la actual Teoría del Derecho (y la falacia intelectualista). 8. Discusión: ¿No es cierto que dichas teorizaciones («estándar») disimulan el decisivo papel que en las argumentaciones jurídicas juegan el Síndrome normativista y los condicionamientos societales efectivos? 9. Excurso: Distintas funciones discursivas de lo «ideal» (puede servir para delinear modelos ya sea de enjuiciamientos, de comparaciones empírico-científicas o de disimulaciones ideológicas).

a una tan máxima e inútilmente pedante como lo es todo ese formulario superfluo [vid. también infra: n. (nota) 53 in fine]. 
IV. CONCLUSIONES FUNDAMENTALES: 10. «Storytelling» como resultado: la Teoría «estándar» de la Argumentación jurídica es una ideología profesional. 11. Epílogo: ¿Es dable tener una teoría realista de la argumentación jurídica?

\section{VISIÓN GENERAL}

Según los autores de esa corriente, Teoría de la Argumentación jurídica, ésta daría cuenta, presuntamente, de cuanto constituye la «técnica» por excelencia empleada por los operadores del Derecho, en especial la de los jueces. Ello se ofrece como explicación — descripción: la práctica jurídica tal como ella es-, pero a la vez se propone como guía —-modelo normativo: exhortaciones a cómo ella debe ser-, para el pensamiento jurídico profesional; por lo general, eso sí, esto es presentado sin discriminar bien entre lo uno y lo otro. Daría la impresión, leyendo a esos autores, que no vale la pena poner de manifiesto diferencias importantes entre esos dos planos. Vale decir, que la «racionalidad» predicada para el segundo —unos modelos ideales - se correspondería igualmente (o poco menos) con la generalidad de cuanto acontece efectivamente en el primero - las prácticas judiciales mismas-; algo así como si se tratara de una sola moneda - discursividad jurídica in genere- cuyas dos caras (razonamiento jurídico ideal/discursos jurídicos efectivos) son gemelas, o cuasigemelas.

En su aplicación a los discursos jurídicos, la Teoría de la Argumentación se refiere principalmente al razonamiento en sede judicial. Estos razonamientos comprenden dos órdenes de cuestiones que, si bien pueden aparecer finalmente combinadas en la fundamentación global, responden a dos órdenes de indagaciones de carácter muy distinto el uno del otro: respectivamente, hechos («es») y normas («debe»). En efecto, allí se trata de: a) comprobar si tales o cuales hechos, o ciertos aspectos de éstos, tuvieron o no tuvieron lugar realmente, y b) determinar si unos criterios normativos (legales, jurisprudenciales, doctrinarios, etc.) son aplicables a esos hechos y en qué forma, de lo cual se siguen qué deberes o derechos sean los invocables jurídicamente.

Si bien caben argumentaciones para discernir aspectos ya sea en uno o en el otro de estos dos planos, los estudios de teoría de la argumentación jurídica se concentran en hacer ver condiciones específicas para obtener los contenidos del plano normativo propiamente. En efecto, las maneras de argumentar examinadas en tales estudios corresponden a razonamientos utilizados para explicitar el sentido de unas normas, dadas por textos legales o consistentes en criterios doctrinales. De ahí que la discusión sobre Teoría de la Argumentación que plantearé en el presente estudio no se refiere para nada a las elucidaciones en sede judicial sobre comprobación o refutación de hechos (por más que sea sola o principalmente esto último, muy a menudo, lo que se encuentra en discusión allí).

En las maneras cómo dicha Teoría la sostienen autores muy citados en los estudios de lengua española para ese campo, ella permite cubrir con un halagador (para la conciencia jurídica profesional) manto de embellecimiento los modos de razonar que cultivan normalmente los juristas. Semejante enfoque teorético se acopla a 
las mil maravillas con la orientación básica del pensamiento jurídico corriente: no menos en aquél que en éste, las formas de encarar sus razonamientos se contentan con examinar sólo ciertos planos esencialmente semánticos del pensamiento jurídico, cual si se tratara de algo así como unas «novelas de conceptos» ${ }^{4}$. Así dichas teorizaciones con respecto a las argumentaciones jurídicas, en los modos - ¡idealistas! - como éstas son presentadas en los escritos de esos autores, en definitiva no significan sino otra forma más de encerrar al pensamiento sobre el Derecho en unos «cielos» ${ }^{5}$ discursivos. Con ello queda fuera de foco, enteramente o poco menos, la pragmática («tierra») ${ }^{6}$ de los discursos jurídicos efectivos, para cuanto en éstos no sea discutir nada más sobre las pruebas materiales con respecto a unos hechos judiciables.

En efecto, tales aproximaciones se ocupan muy poco o nada de dirigir la mirada hacia las realidades psicosociales que en la práctica condicionan, decisivamente, la producción de los discursos desempeñados por los operadores jurídicos. Ellas dejan confinado entre bambalinas nada menos que lo siguiente, como si todo eso no influyera para nada o muy poco en los discursos mismos efectuados por la judicatura: infraestructura material de los tribunales (superabundancia de casos por resolver, kafkiano tramiterío burocrático interno), mentalidades de los propios jueces (precomprensiones ideológicas, prejuicios, temperamentos), sometimiento intelectual de los operadores jurídicos a sus trucos retóricos corrientes [«Síndrome normativista» (abrev: Síndrome) ${ }^{7}$ y demás], influencia de presiones personales y sociales en general. Menos que menos se interesan dichos estudios por indagar qué repercusiones reales tenga el empleo de unos u otros argumentos invocados, qué consecuencias sociales efectivas se siguen de elaborar los discursos según unas u otras formas en los razonamientos jurídicos «vivientes». Así la «argumentación» jurídica — convenientemente estetizada - que nos presentan tales teorías viene a constituirse, en definitiva, ni más ni menos que en un expediente teorético de disimulación frente a las prácticas más comunes — ¡las más efectivas! — de los razonamientos efectuados en el ejercicio profesional normal por los operadores del Derecho.

Es verdad que esas prácticas consisten, al menos su superficie manifiesta, en unos ejercicios de argumentación. Sólo que:

a) Estas argumentaciones en sí mismas no suelen responder, de hecho, a los parámetros aséptico-idealistas de que se ocupan los trabajos de aquellos teóricos; en la práctica ellas suelen ser, en muy buena parte, de orden esencialmente retórico-contingente, basadas en falacias del Síndrome (infra, $\mathbb{3}$ ).

b) En dichos estudios, las «argumentaciones» son examinadas principalmente (por no decir únicamente) en cuanto a cuál sea su aceptabilidad en sí y por sí; vale decir, como unos juegos semánticos autosuficientes.

${ }^{4}$ Vid. 2011a, esp. VII.2. Cuando, como en esta nota, se señala solamente el año de edición del trabajo referido, sin indicación expresa de autor, se trata de alguno de los estudios consignados al final del presente artículo, en la lista: Trabajos complementarios del autor.

${ }^{5}$ Cfr. R. vON JHERING, Broma y veras en la Jurisprudencia (trad. T. A. Banzhaf) (or. alem. 1860-1884), Buenos Aires, Parte III, 1974. Las palabras de ese autor ubicadas en el motto del presente estudio se encuentran en la 307 [negr.(negritas) añadidas por mí, e.p.h.) de dicha obra.

6 Vid. el sitio señalado en la nota anterior.

7 Infra, $\$ 3$. 
c) En cambio, se hace caso omiso de indagar cuáles son las consecuencias empíricamente comprobables —ipragmática lingüística! — en cuanto a efectos reales (los beneficiosos y también los perjudiciales) que unas u otras argumentaciones efectivamente presentadas en los tribunales, y en general los modelos que en esos estudios se proponen para ello, tienen sobre los propios seres humanos que reciben estos efectos (si los hay) en carne propia.

De ahí que, y poco importa las buenas intenciones que posiblemente mueven a sus autores, la clase de estudios sobre la argumentación jurídica que están en boga en Teoría del Derecho se dedican a algo así como «tocar la lira» ${ }^{8}$ ante $a$ ) y $b$ ). Con esa música, arrulladora para la autocomplacencia tanto de los círculos académicos ocupados en entonarla como también de la profesión jurídica en general, el razonamiento cultivado por la doctrina normal del Derecho y en los tribunales está de parabienes, ¡no faltaba más! Hoy por hoy, es ésa la ideología de autolegitimación más popular en el gremio de los juristas.

Por supuesto, no todo lo que dicen esas teorías es erróneo. Cabe reconocer que ciertos aspectos allí señalados no dejan de desempeñar también un papel en los razonamientos jurídicos; empero, aun siendo así, en la realidad suele suceder de maneras subordinadas a, y decisivamente limitadas por, aquellos otros factores de los cuales ellas no se ocupan. También es cierto que, a pesar de todo, sería muy exagerado decir que el razonamiento jurídico es simplemente extrarracional o del todo antirracional. Son cuestiones de grados: en algunos aspectos y casos es mayor, en otros es menor, en la medida en que esos razonamientos se ven afectados por dicho Síndrome y en general por encoger sus argumentos a moverse en unos niveles esencialmente semántico-dogmáticos. El pecado genérico de las teorizaciones «estándar» sobre las argumentaciones jurídicas es enfocarlas como si semejantes gradaciones no existieran, o fueran mínimas y más bien excepcionales; en fin, como si la importancia de éstas fuese baladí para examinar tales argumentaciones en sí mismas.

Por el contrario, si cabe una teoría realista de la argumentación jurídica, su principal énfasis será muy otro: poner de manifiesto cómo tales o cuales especies de argumentaciones habituales en ese campo, aun cuando lleguen a seguir unos requisitos formales «dialógicos», empero sólo son débilmente (deficitariamente) racionales o razonables, por encontrarse subordinadas al Síndrome (infra, $\mathbb{S} 3$ ) y demás. En una palabra: mientras la teoría «estándar» se ocupa de cómo las argumentaciones jurídicas deberían ser, toda teoría realista prestará mucha atención (infra, $\$ 11$ ) a cómo ellas son en las propias prácticas cotidianas de los operadores jurídicos corrientes.

En las secciones que siguen paso a explicar más detenidamente las tesis que he adelantado en esta introducción.

${ }^{8}$ Infra, nota 75 . 


\section{[I]}

\section{TEORÍA «ESTÁNDAR» VERSUS «SÍNDROME NORMATIVISTA»}

\section{RASGOS FUNDAMENTALES DE LA CONCEPCIÓN ILUSIONISTA SOBRE LAS ARGUMENTACIONES QUE EFECTÚAN LOS JURISTAS: SU TEORÍA «ESTÁNDAR»}

Como teorías de la argumentación caben dos grandes tipos de enfoques. Tienen su origen principal, respectivamente, en dos obras fundamentales publicadas en 1958: Perelman y OlBRECHTS-TyteCA, La nouvelle rhétorique. Traité de l'argumentation; Toulmin, The Uses of Argument. La orientación de la primera de esas obras es de corte minuciosamente analítico-realista, de donde resultan implicaciones críticas radicales con respecto a los discursos examinados. La segunda obra, en cambio, está centrada en presentar y justificar un modelo ideal para esos discursos, los de la llamada «Razón práctica».

Pero el impulso básico del giro hacia la visión «argumentativista» sobre el razonamiento jurídico en particular, por cuanto hace a la decisiva influencia de PERELMAN en tal sentido, no responde a la «vis» dominante en dicho Traité. Con esta sensacional monografía había culminado la primera etapa del pensamiento de ese autor, dentro de la cual el otro estudio insustituible fue su desmistificador análisis sobre los usos del término «justicia» (De la justice, 1945) ${ }^{9}$. En cambio, la aplicación y prolongación de ideas de dicho autor en estudios de Teoría del Derecho responde sobre todo a la tesis central sustentada en otros trabajos suyos, ulteriores, que por cierto no son nada críticos — ies todo lo contrario! — con respecto a los razonamientos típicos de la profesión jurídica: básicamente, su libro Logique juridique. Nouvelle réthorique (1967). Complementariamente, la corriente «argumentativista» relativa al Derecho se afinca también en la cuestión de la «tópica» jurídica (punto de vista introducido por el clásico estudio de VIeHWeg, Topik und Jurisprudenz, 1953); hasta el propio PereLman incluye tal dimensión en el mencionado libro.

En efecto, las sucesivas teorizaciones sobre la argumentación jurídica no adoptaron una dirección similar a la del Traité, sino que están emparentadas sobre todo con la actitud intelectual de PERELMAN en la segunda etapa (bien puede decirse así) de su trayectoria intelectual, cuando sus estudios dieron un giro hacia perspectivas sustancialmente contemporizadoras, en trabajos como Logique juridique... Entonces sus exámenes, si bien siguen empleando ciertos conceptos básicos de la etapa anterior (orador y auditorio, adhesión y persuasión, etc.), hicieron a un lado los «filos» inconformistas. Pasaron a constituirse más bien en una apología del pensamiento jurídico profesional; están dirigidos nada menos que a justificar la pertinencia intelectual de este mismo, sus modos tradicionales de razonamiento, esencialmente análogos (cuando no iguales) a los de hoy.

Al decir «Teoría de la Argumentación», en general, aquí entiendo referirme a esa última clase de aproximaciones con respecto a los razonamientos jurídicos, las de

\footnotetext{
9 C. Perelman, De la justicia (trad. R. Guerra) (ed. or. fr. 1945), México, 1964.
} 
orientación predominantemente idealista-escapista. En efecto, tales aproximaciones se hermanan, todas ellas, en cuanto a presentar esos razonamientos de unas maneras que dejan fuera de foco la falaciosidad de los principales recursos comunes de carácter retórico-erístico en que suele enhebrarse la «racionalidad» de los argumentos invocados por los juristas. Quedan disimulados, así, los básicos vicios de pensamiento que suelen dominar en discursos habituales de sus operadores profesionales reales, quienes en esos estudios ceden el lugar a unos razonadores ideales ( $; \ldots$ pero sin aclarar que éstos son tales, no los locutores empíricos de la profesión jurídica tal como ella es ejercida en la práctica!).

Sí, el impulsor básico del giro hacia la visión «argumentativista» sobre el razonamiento jurídico fue ese Perelman ya «sin filo». Pero no menos cierto es que desde antes, contemporáneamente al propio Traité, hubo también otro trabajo fundamental en la materia: el mencionado estudio de Toulmin. A diferencia del desmistificador detallismo realista sobre argumentaciones «vivientes» que despliega la excepcional monografía de PERELMAN y OlBRECHTS-TYTECA, en The uses... queda prefigurado el culto a la visión idealizada de la Razón práctica, pues también TOULmin, allí, la percibe como conformada esencialmente por unas argumentaciones bien «racionales» (si bien subrayando que tal «racionalidad» es de otro tipo que la propia de las inferencias meramente lógico-formales y también que aquellas usadas por las ciencias de la naturaleza).

Ya en dicho estudio de Toulmin, el cual por cierto es iluminador en muchos aspectos, se procede a encarar como si fueran la misma cosa, implícitamente, o en todo caso no se distingue consecuentemente entre: $a$ ) unas estructuras $i d e a l e s$ señaladas para argumentar; y, en cambio, $b$ ) cómo funcionan realmente las argumentaciones «vivientes» que constituyen los discursos habituales de la política, el Derecho, los juicios éticos y otros. En efecto, también ese autor sucumbió allí a la candidez de tomar como modelo por excelencia de «procedimiento racional», ni más ni menos que la retórica jurídica profesional — sin parar mientes en el Síndrome (infra, $\$ 3$ ) y demás «celadas» lingüísticas que la vertebran sustancialmente-, como tampoco se fija en las mitificaciones simbólico-ideológicas que esos argumentos, justamente ellos mismos, recogen y revalidan como la cosa más natural del mundo ${ }^{10}$ :

«... take as our model the discipline of jurisprudence. Logic (we may say) is generalised jurisprudence. (...) [W] shall aim, in a similar way, to characterise what may be called "the rational process", the procedures and categories by using which claims-in-general can be argued for and settled» ${ }^{11}$.

Da toda la impresión de que Toulmin no tenía noticia (en todo caso, pareciera haber sido así por entonces) de que existen estudios realistas sobre el razonamiento jurídico. Pienso eso, no simplemente porque dicho autor no se ocupa allí de tales estudios, sino sobre todo por su idea de tomar nada menos que como el «modelo» por excelencia de «rational process» al razonamiento jurídico, presunción que resulta

${ }^{10}$ Léase, por todos, el imprescindible libro de T. W. ARNOLD, The Simbols of Government, New York, 1962 (ed. or. 1935). Quienes puedan consultar trabajos en lengua alemana no debieran pasar por alto el excepcional estudio de H. Neumann-Duesberg, Sprache im Recht (El lenguaje en el Derecho), Münster, 1949 — inada que ver, claro está, con «construcciones» como las de AlEXY y Cía.!-

${ }_{11}$ S. Toulmin, The Uses of Argument, 7 [curs. (cursivas) añadidas por mí, e.p.h.], 1958. 
difícilmente conciliable con tener conciencia acerca de cómo están conformados estos discursos en la práctica ${ }^{12}$. Esa concepción suya del razonamiento argumentativo es todo lo «celestial» que hace falta para conformarse con tomar como referencia la presentación que de las razones jurídicas ofrece la law in books (R. Pound) ${ }^{13}$. En tal sentido, este estudio clásico de Toulmin viene a ser el antecedente básico de eso que ATIENZA llama «teoría estándar» de la argumentación jurídica (AlEXY y otros). Como veremos, esta última se encuentra conformada por aquellas orientaciones que, dentro de la moderna Teoría del Derecho, se ocupan de maquillar el razonamiento jurídico profesional mediante un tipo propio de idealizaciones, aquellas que responden al sello de presentarse como específicamente argumentativo-razonabilistas.

Los principales fundamentos teoréticos de la presentación idealizadora que en la Teoría del Derecho domina hoy abrumadoramente acerca de las argumentaciones jurídicas se corresponden, como fuere, con las tesis básicas del segundo PERELMAN. Eso sí, la nitidez con que este último expone sus puntos de vista sobre esa temática los hace diáfanos para someter a examen lo esencial de esa posición, aprovechando que ahí ella se encuentra planteada de la manera más aguda y con entera llaneza. Considero que PerELman sigue siendo el pensador fundamental entre quienes han adoptado tal orientación, en general; es el más directo y también el menos fantasioso de todos ellos. A decir verdad, los trabajos ulteriores dentro de esa corriente no han agregado nada decisivo, sólo unos u otros detalles secundarios (que en no pocos estudios hacen que éstos sean sólo más especiosos), a eso de PERELMAN y a lo de Toulmin.

$* * *$

Según Toulmin y también para PeRELMAN (2. ${ }^{a}$ etapa), el razonamiento jurídico tal como es — vale decir, en virtud de su naturaleza argumentativa - constituye, tanto por su perfectamente adecuada legitimidad intelectual como por la aplicación general de tales formas de razonar en la práctica profesional, la vía ejemplar para resolver de la mejor manera posible las cuestiones sometidas a los tribunales, y hasta muchas otras de la Razón práctica en general. Las observaciones que al respecto pasaré a efectuar, en lo sustancial, son aplicables asimismo a las exposiciones de los autores que adoptan tal línea de pensamiento actualmente; si bien casi todos ellos, a diferencia del propio PERELMAn, suelen abundar en unas u otras suertes de pedanterías que disimulan el verdadero fondo — una pseudorracionalidad— del asunto.

¿Hace falta nombrar autores más mencionados hoy día que Perelman? Se trata, en definitiva, de quienes lideran lo que ATIENZA ha denominado: la teoría «estándar» de la argumentación jurídica. Este último destaca, para definir tal teoría:

12 Sin embargo, años después nos encontramos con que el mismo autor formula unas observaciones que van en sentido muy distinto, y por cierto son realistas, al referirse críticamente a fantasías razonabilistas como la de HABERMAS-AleXY. Dice entonces: es «... algo así como poner el carro delante del caballo..., el caballo es la comprensión de la naturaleza de la forma de vida, de la naturaleza del papel que el Derecho desempeña en la vida social...»; «... cualquier análisis de la argumentación jurídica tiene que entender la naturaleza de esta argumentación sobre el trasfondo de un análisis de la práctica jurídica, del papel del Derecho en la vida social...» [cit. en M. ATIENZA y M. JIMÉNEZ REDONDO, «Entrevista con Stephen E. Toulmin» (trad. M. Jiménez Redondo), Doxa, núm. 13, 1993, 329-356, líneas tomadas de las 330 y ss. (versalitas e.p.h.)].

13 Cfr. K. L. Llewellyn, «A Realistic Jurisprudence - The Next Step», Columbia Law Review, t. 30, 1930, 431-465. Para una síntesis en español de dicho estudio puede verse 2003 (\$ 51) o 2007b (\$247). 
[...] catorce «rasgos característicos de esa nueva concepción», configurados centralmente en torno de unos u otros ángulos de credulidad racionalista básicos. Así: «4) [...] la importancia que se concede a la interpretación que es vista más que como resultado, como un proceso racional y conformador del Derecho. [...] 10) [...] la idea de que la razón jurídica no es sólo razón instrumental, sino razón práctica [(i.e.:) no sólo sobre medios, sino también sobre fines (cognitivismo axiológico)] [...] [...] 13) [...] la convicción de que existen criterios objetivos [como el principio de universalidad o el de la coherencia o integridad (jtales fórmulas vacías o semivacías!)] que otorgan carácter racional a la práctica de la justificación de las decisiones, aunque no se acepte la tesis de que existe una respuesta correcta para cada caso. [...] 14) [...] una moral racionalmente fundamentada (cognitivismo axiológico)...» ${ }^{14}$.

Por mi parte, considero del caso completar tal enumeración con un rasgo adicional que es singularmente revelador. Justamente éste, el ignorado (o en todo caso callado) por los «argumentativistas», significa llamar la atención sobre algo que es de lo más sintomático para diferenciar a fondo dicha «nueva concepción» frente a cualquier mirada propiamente realista sobre los discursos jurídicos profesionales:

\section{5) japartar la mirada frente al Síndrome normativista!}

Este decisivo expediente de evasión [cuyos contenidos específicos detallaré más abajo: $\$ 3$ ] vertebra a todas esas teorías «estándar», hermanándolas de raíz en su condición de racionalizaciones escapistas, más allá de las diferencias que entre unas y otras puedan darse en cualquier aspecto adyacente. Desde luego, esto no significa afirmar que esos autores no se hayan referido jamás, en unas líneas de sus publicaciones, a alguno o algunos de los ítems que componen ese Síndrome. Sí, pueden haber aludido a algo de eso, aunque sea de paso (nada importa que sin llamarlo así). Hasta estimo bastante probable que lo hayan hecho al menos con respecto a uno de esos puntos, el carácter convencional del lenguaje ${ }^{15}$, como personalmente lo he detectado en algunos de esos trabajos. Me extrañaría que la mayoría de esos autores no tengan ninguna noticia de ello ${ }^{16}$, simplemente. Pero el asunto es: no si lo saben o no lo saben, o si acaso lleguen a chistar algo sobre ello, sino cuál es el papel que lo de estar atento al Síndrome tenga en las enseñanzas fundamentales ofrecidas mediante tales teorizaciones. En todo caso, de hecho es como si no lo supieran. Sea por los motivos que fuere, los conocimientos al respecto no se ve que desempeñen ningún auténtico protagonismo en las elucidaciones que acerca del pensamiento jurídico proveen tales estudios.

\section{Suplemento: Autores que cultivan la teoría «estándar» de la argumentación jurídica.}

«De entre las teorías que han aparecido en estos últimos años, dos de ellas (elaboradas por N. MACCORMICK y por R. AlEXY), son, en mi opinión, las que tienen un mayor interés y quizás también las que han sido más discutidas y han alcanzado una mayor difusión..., estas dos concepciones que, de alguna manera, vienen a constituir lo que podría llamarse la teoría estándar de la argumentación jurídica. De hecho, otras teorías formuladas aproximadamente en las mismas fechas y que también han conocido una considerable difusión —como las de A. AARNiO (1987) y A. PECZENIK (1989)— podrían considerarse como desarrollos de la de AleXY o, por lo menos, vienen a resultar compatibles, en lo esencial, con aquella teoría. [...] Ello no quiere decir, por otro lado, que MACCORMICK y ALEXY representen, ni mucho

${ }_{14}$ Cfr. M. AtiEnZA, El Derecho como argumentación, Concepciones de la argumentación, Barcelona, 2006, 55 y ss.

15 Vid. infra, $\mathbb{S} 3$ (poco después de la nota 21, el punto 1.b).

16 Vale decir, salvo DwORKIN ( $c f r$. HABA, 2001a/2009a), y no muchos más (al menos entre los autores bastante nombrados). 
menos, puntos de vista antagónicos con respecto a la argumentación jurídica o, en general, con respecto a la teoría del Derecho [...] (sino que esos dos autores) llegan a formular al final concepciones de la argumentación jurídica esencialmente semejantes» (ATIENZA, 2006a, 168 y ss., cursiva añadida). «Y, de hecho, muchos otros autores procedentes de tradiciones filosóficas o jurídicas muy diversas entre sí (el positivismo jurídico, el realismo, la teoría crítica, la hermenéutica, el neomarxismo, etc.) han defendido en los últimos tiempos tesis que, en el fondo, no se diferencian mucho de las de DwORKIN; pienso en autores como MacCormick, Alexy, Raz, Nino o Ferrajoli (y es el caso también de AtienZA)» (AtienZA, 2006b, 55).

Hemos visto que ATIENZA señala catorce «rasgos característicos de esa nueva concepción». Es verdad que él no deja de efectuar la precisión siguiente: «Ninguno de esos autores asume todos los rasgos que ahora señalaré, pero sí la mayoría (o, al menos, un número significativo) de los mismos que, por lo demás, están estrechamente ligados con el enfoque argumentativo del Derecho» (op. cit., 55 y ss., cursiva añadida). Por lo demás, téngase en cuenta sobre todo el rasgo (15) (supra), precisamente el que no figura en dicha lista. Tal omisión es plenamente compartida por todos esos autores (empezando por el propio ATIENZA).

EN SÍNTESIS: Los modelos de argumentación presentados en los estudios «estándar» de Teoría del Derecho disimulan cómo operan los razonamientos jurídicos reales. Estos últimos ceden en ella el sitio a unas fórmulas de «racionalidad» o «razonabilidad» extraempíricas, propias de unos operadores jurídicos ideales, supuestamente ajenos al Síndrome. Por lo mismo, en tales aproximaciones quedan igualmente fuera de foco las condiciones de base reales — limitaciones materiales de los tribunales, ideologías, presiones sociales, enseñanza principalmente dogmática del Derecho- a que están subordinados los razonamientos jurídicos efectivos.

Pues bien, lo decisivo es tener claro en qué «terreno» — realismo vs. ilusionismos- ${ }^{17}$ cada estudio toma asiento para sus exámenes sobre discursos jurídicos. Esos terrenos se diferencian de manera neta el uno del otro, en cuanto a qué se consigue «ver» al ubicarse en cada uno de ellos respectivamente. Frente a tal alternativa, cada autor no puede evitar tomar posición, quiéralo o no, sea explícita o implícitamente, de unas maneras u otras. Según de qué lado de la zanja divisoria, en cuanto al tipo básico de aproximación, estén ubicados los contenidos principales de los estudios en cuestión, eso será lo que «verán» respectivamente cada uno de ellos mismos. Esto es: o bien, los estudios no dejan de considerar como cuestiones ineludibles - iy centrales! - lo puesto de manifiesto en los exámenes no «embellecedores» con respecto a dichos discursos [Kantorowicz, Llewellyn (1. a etapa), Frank, Arnold, SCHeuerLE, RÜTHERS, CARRIÓ, TARELlO, NieTO, etc.] ${ }^{18}$; o bien, en cambio, se satisfacen con apartar la vista de tales observaciones, que por cierto no resultan confortables para la «buena conciencia» gremial de la profesión jurídica. Cuál de esas dos actitudes se adopte, marca la diferencia clave entre las reflexiones propiamente realistas acerca del Derecho —inclaudicablemente «incómodas»—y todas las demás teorizaciones al respecto. La teoría «estándar» sobre la argumentación jurídica pertenece a este segundo género de aproximaciones, esencialmente embellecedoras en sus consideraciones sobre los razonamientos jurídicos profesionales.

17 Vid. 2000.

${ }_{18}$ Cfr. también 2006a, passim. 


\section{EL SÍNDROME NORMATIVISTA}

Es sabido que la discursividad jurídica no ofrece, ni puede llegar a ofrecer, ciertas rigurosidades metodológicas como unas que caracterizan a las ciencias «fuertes» (lógica formal y matemáticas, ciencias de la naturaleza). Las ciencias sociales en general, y la del Derecho entre ellas, son ciencias «débiles»; si bien no carecen de controles metodológicos propios, esos «métodos» suyos (si quiere llamárseles así) son señaladamente menos estrictos y uniformes, en sus empleos corrientes, que los procedimientos estandarizados a que recurre la ciencia «normal» (T. S. KuHN) en las disciplinas del primer tipo.

Los autores «argumentativistas» ponen el mayor énfasis en subrayar tal diferencia. En cambio, mantienen silencio sepulcral sobre una segunda diferencia, no menos verdadera y no menos fundamental que aquella primera. Esto es, la disparidad radical que hay entre el razonamiento jurídico normal y todas las demás ciencias sociales, en cuanto a lo siguiente: aquél suele valerse de una serie de «celadas» (WITTGENSTEIN) del lenguaje ${ }^{19} \mathrm{y}$ en general de ciertos non sequitur lógicos, parte de lo cual responde a figuras específicas de la «técnica» jurídica (p. ej., invocar «naturalezas» jurídicas) y otra parte proviene del pensamiento ideológico vulgar; en cambio, tales expedientes no dominan primordialmente —o al menos no lo hacen de manera generalizada - ni siquiera en dichas ciencias, por más «blandas» que ellas sean en tales o cuales aspectos ${ }^{20}$. $\mathrm{Ni}$ en la Sociología, ni en la Economía, ni en la Lingüística, ni en la Psicología, ni en la Antropología, ni en la Historiografía, y demás, «se vale» recurrir a aquellas celadas retóricas, que han sido desnudadas como tales precisamente por algunas de esas disciplinas en especial (análisis del lenguaje ordinario, crítica de las ideologías, epistemología del conocimiento científico-social).

En otros sitios he presentado un cuadro general de cuáles son, a mi juicio, los principales tipos de falacias que se hallan corrientemente en discursos jurídicos profesionales. Ellas conforman lo que he llamado: el Sindrome normativista. No quiere decir que lo consignado en éste agote las deficiencias que se presentan en tales discursos, pero sí apunta a una serie de vicios de razonamiento que son frecuentes ahí. Tampoco es que tales falacias, y otras falencias, se den todas ellas en cada uno de esos discursos, sino que son unas u otras, en medidas variadas, según casos y especies de cuestiones jurídicas encaradas; de todos modos, es raro que no se presenten al menos alguna o varias de ellas, sean cuales fueren, al resolver las cuestiones jurídicas debatidas efectivamente en los tribunales, así como también abundan en la dogmática jurídica en general.

Quiérase o no, el Síndrome constituye la base de «(ir)racionalidad» más general que se hace presente, una y otra vez, en los modelos de pensamiento que los juristas profesionales ponen en juego para desempeñar su labor discursiva específica como tales. Se trata de lo siguiente, sobre todo ${ }^{21}$ :

19 Cfr. 2003, esp. t. I, cap. II y ap. 2; o bien, más breve, 2007b, sec. D.I-II. 2006 b.

${ }^{2}$ Cfr. 2006a, sec. B.IV; para desarrollos más amplios, 1993 y 1995 (o sus reelaboraciones ulteriores) y

21 Para desarrollos más pormenorizados al respecto, vid. 2006a, sec. C.II. 
1. Énfasis principal reservado a unas controversias terminológicas, con base fundamentalmente en:

a) Pasar por alto la diferencia clave entre cuestiones de hechos y cuestiones de palabras.

b) Desconocer —o al menos disimular- el carácter convencional del lenguaje y sobre todo el carácter personal de la elección efectuada por el propio intérprete de los textos jurídicos — si bien tal opción está limitada, de hecho, a no ultrapasar los márgenes (condicionamientos sociolingüísticos) de que éste disponga efectivamente en la práctica-.

2. Platonicismo normativista como principal técnica general de examen, unas construcciones doctrinarias ubicadas en el «cielo» (JHERING); con omisión de los tests propiamente empírico-científicos, o recurso muy insuficiente a éstos, para aquilatar cómo los criterios ahí postulados funcionen (o no) en la realidad práctica.

3. Fundamentación jurídica mediante peticiones de principios y la aceptación simplemente dogmática —esto es, no empírico-crítica — de las ideas básicas manejadas allí.

4. Terminología «técnica» de tipo esencialista («naturalezas» jurídicas, clasificaciones y definiciones tomadas apriorísticamente como válidas per se).

5. Faltas de distinción entre «es» $\mathrm{y}$ «debe», las cuales provocan confusiones entre lo que corresponde respectivamente en atención a lo uno y a lo otro.

6. Recurso a un multicolor repertorio de conceptos jurídicos bastante indeterminados, que se invocan como si cada uno de ellos remitiera a un solo sentido identificable inequívocamente; entre los cuales a menudo figuran a título de última ratio, pseudometodológica, ciertas fórmulas vacías persuasivas con funciones de comodín retórico omniubicable («unidad» del Derecho, «proporcionalidad», «equilibrio», «racionalidad»o «razonabilidad», «sana crítica»...).

7. Recepción espontánea de universos simbólicos propios del pensamiento social vulgar (así: «justicia»y «equidad», «bien común», «interés» social o de «la» colectividad»o «nacional») 22 , a los que sin ninguna precaución analítica se recurre como asiento de las tesis propugnadas; pasando así por encima de precisiones decisivas que en la Sociología, la Psicología, la Lingüística y otras disciplinas se han aportado para desmitificar el uso de esos términos.

Cualquiera de estos ítems desempeña papel decisivo, a veces son unos y a veces otros, bajo variadas modalidades, tanto en la doctrina jurídica en general ${ }^{23}$ como en numerosas resoluciones judiciales. Sin embargo, en los estudios sobre Teoría de la Argumentación nos encontramos con muy poca o ninguna referencia a la intervención de dichos elementos en las argumentaciones de los juristas. Poco importa, desde luego, cómo se le llame al conjunto de tales elementos o no asignarles ninguna etiqueta de denominación global; pero lo cierto es que si uno no conoce más que aquellos estudios, o sólo los de otras corrientes no menos escapistas de Teoría del Derecho (RAWLS ${ }^{24}$, lógica

\footnotetext{
22 Vid. 2007b: esp. secs. B, C y D.

23 Esto se puede apreciar muy netamente, p. ej., en los planteamientos del autor que en la actualidad es el más conocido propagandista del normativismo jurídico: $c f r$. 2001b (mejor 2009a).

24 Cfr. $2009 \mathrm{~b}$.
} 
deóntica y semióticas ilusionistas en general ${ }^{25}$, teorías de sistemas $^{26}$, FERRAJOLI ${ }^{27}$, etc.), todo se ve como si los elementos del Síndrome no interviniesen en las argumentaciones jurídicas normales; o en todo caso, como si ahí la presencia de aquél fuese de importancia muy secundaria para determinar las orientaciones y las conclusiones mismas de los razonamientos basados en tales preconcepciones. Todo ello sin perjuicio de reconocer que, por cierto, en unas ramas del Derecho (señaladamente Derecho internacional público y Derecho constitucional) la presencia del Síndrome es mucho más frecuente y preponderante que en otras (Derecho penal, Derecho civil, Derecho registral, etc.).

\section{[II]}

\section{CARÁCTER SUPRAEMPÍRICO DE LAS TEORÍAS ARGUMENTATIVO-«RAZONABILISTAS»}

\section{LA APOLOGÍA SUBREPTICIA}

Señaladamente en Logique juridique. Nouvelle rhétorique ${ }^{28}$, PERELMAN expuso las razones fundamentales que se invocan para encomiar cómo funcionan las argumentaciones jurídicas. Ninguno de los autores «razonabilistas» posteriores ha logrado añadir, hasta donde tengo conocimiento, razones de mayor peso que las señaladas en tal sentido por aquél. Eso sí, ellos han venido a enredarlas con toda suerte de pedanterías (... pour la galérie), o en el mejor de los casos a complementarlas secundariamente con detalles que no cambian lo principal. Los exámenes de dicho autor siguen siendo los más atendibles dentro de esa gran corriente, tanto más cuanto que aparecen respaldados por una rica cantidad de ejemplos extraídos de los tribunales: los razonamientos jurídicos tal y como suelen llevarlos a cabo, o en todo caso presentarlos así, los jueces. Sin embargo, esta presentación ofrecida por PERELMAN no deja de ser más bien engañadora, disimula la verdadera naturaleza que tales argumentaciones suelen tener en la práctica jurídica. Paso a exponer directamente mi crítica al respecto, en consideración a los conocidos puntos de vista de dicho autor ${ }^{29}$. Esa crítica es extensible (... et à plus forte raison!) a los autores, en general, que pregonan la teoría «estándar» (basta con efectuar el siguiente experimento mental: suponiendo que las ideas centrales de PERELMAN fueran esencialmente erróneas, asimismo caerían por su base todas o la mayor parte de las principales tesis promovidas por autores más recientes, como ALEXY, AARNIO, ATIENZA y muchos otros).

Por lo pronto, importa llamar la atención sobre el hecho de que esa versión de PERELman sobre las características básicas del razonamiento jurídico no constituye simplemente algo así como una mera descripción al respecto. Es mucho más que eso. La manera cómo dicho autor nos presenta lo sustancial — según él— de tales razona-

25 Cfr. 1996a y 2000.

${ }^{26}$ Cfr. 2006a, sec. C.II.1.

27 Vid. supra, nota 3.

${ }^{28}$ La versión española es C. Perelman, La lógica jurídica y la nueva retórica (trad. L. Díez-Picazo), Madrid, 1979.

29 Pienso que no es necesario reiterar aquí esas razones, suficientemente difundidas entre quienes se interesan por esta materia. La mejor presentación general que conozco sobre las ideas de PERELMAN es el diáfano librito de A. L. Gómez GIRALDO, Seis lecciones sobre Teoría de la argumentación, 3. ${ }^{a}$ ed., Cali (Colombia), 2003. 
mientos contiene cierta apología, que casi siempre él la expresa en forma más bien velada, acerca del estado de cosas caracterizado así. En otro sitio, el propio PERELMAn llega a señalar sin tapujos ese carácter apologético: $c f r$., p. ej., el artículo en donde subraya «Lo que el filósofo (¡y no solo éste!) puede aprender por el estudio del Derecho» ${ }^{30}$. También GADAMER consagró un apartado de su principal obra a destacar «El carácter paradigmático [i. e., ejemplar] de la hermenéutica jurídica» ${ }^{31}$. Hasta estudios tan analíticos como el clásico de TOULmin ${ }^{32}$, o p. ej., un excelente artículo de POIRIER sobre la cuestión $^{33}$, si bien no sería justo calificarlos de propiamente apologéticos con respecto al pensamiento de los juristas, pueden ser usados en apoyo de posiciones semejantes; también POPPER había señalado ya algo por el estilo (La lógica de la investigación cien-

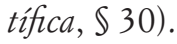

PERELMAN da por sentado que el pensamiento jurídico es y siempre será, como por esencia, incompatible con la sujeción a métodos propiamente científicos; y para referirse a éstos echa en un mismo saco, sin más, los de la lógica formal con los de las ciencias empíricas en general. Ahora bien, sobre todo en cuanto a estas últimas no es indiscutible, por cierto, que no se pueda llegar a incorporar unos métodos como aquéllos en el campo de las llamadas ciencias del espíritu: tanto para probar ciertos hechos o regularidades - la Sociología, por ejemplo, nos ofrece muestras patentes de ello-, como también en combinación con unos axiomas valorativos para extraer ciertas conclusiones normativas bien demostradas ${ }^{34}$. La posibilidad de que métodos análogos puedan o no llegar a ocupar también un sitio de importancia en la esfera del pensamiento jurídico es una pregunta abierta al futuro: ante todo en cuanto a la elaboración o adaptación de dichos métodos, pero además ( ¡casi nada!) por cuanto hace a la propia voluntad de los juristas para emplearlos llegado el caso. Puesto que PERELMAN ni siquiera plantea esta otra posibilidad, él no discute sus condiciones teoréticas ni tampoco sus obstáculos político-sociales, esa descripción suya, decididamente acrítica, que nos ofrece del quehacer jurídico funge, por tal unilateralidad, como una justificación —ideología profesional — del dominio absoluto de la tradición esencialmente normativista (Síndrome, etc.) en la metodología jurídica ${ }^{35}$.

No es convincente su afirmación de que, salvo si se acepta un camino como el señalado por la nouvelle rhétorique, no quedaría otra salida, para los juicios prácticos en general, que dejarlos librados a la irracionalidad pura y simple. El problema no afinca en decidir si hemos de llamarles, o no, «razonables» a las fundamentaciones del tipo que señala Perelman. Lo interesante sería saber qué garantías —al menos en cierta medida - estarían aquéllas en condiciones de brindarnos para que, por dichas vías, se obtengan unas conclusiones menos azarosas que las calificadas de irracionales. Sea como sea, lo cierto es que tales «garantías» estarán dadas en medida muchísimo mayor

30 C. Perelman, Droit, Morale et Philosophie, Paris, 1968, $\mathbb{S}$ XI. Cfr. también, del mismo autor, Justice et raison, Brussels, 1963, cap. XVII («Ce qu'une réflexion sur le droit peut apporter au philosophe»).

${ }^{31}$ H.-G. Gadamer, Verdad y Método (trad. A. Agud Aparicio y R. de Agapito), Salamanca, 1977, cap. 10.3. Vid. también mis comentarios sobre esa obra: sobre todo, 1978 -recogido parcialmente en 1982, 1990 (ap. 4) y 2003 (\$ 46.b/e)—.

32 Supra, nota 11.

33 R. POIRIER, «Rationalité juridique et rationalité scientifique», Archives de Philosopbie du Droit, t. 23, $1978,11-34$

${ }_{34}$ Cfr. 2006a, sec. C.III.5. Mucho más circunstanciadamente: 1980 y 2010a (sec. F.II).

${ }^{35}$ Cfr. 2006a, sec. C.II. 
si conseguimos remitirnos a regularidades de orden científico-empírico, no a unos meros juicios de valor no susceptibles de verificación intersubjetiva, para determinar las condiciones de validez de dichos razonamientos. No es cuestión de pasar por alto la gran incertidumbre, iy manipulabilidad!, de lo que pueda ser llamado «razonable» ${ }^{36}$. En cambio, ciertos juicios de valor instrumentales, si son tratados científicamente como tales (racionalidad weberiana de medios a fines) ${ }^{37}$, no se resignan a lo meramente «razonable» (donde las soluciones que son calificadas así por unos, mientras otros le llaman así a las contrarias); sino que aquellos juicios específicos están en condiciones de ser resueltos en formas racionales propiamente, esto es, razonamientos que son neta y uniformemente intersubjetivos entre los expertos de la materia considerada ${ }^{38}$.

Las diferencias en cuanto al camino que se elija importan - iy mucho! - en el plano beurístico. Lo de llamarse a conformidad con una «argumentación», y cubrirla mediante el prestigio de la palabra «razonable», no significa, de hecho, que ese pensamiento se aparte verdaderamente de las fallas de racionalidad efectivamente dominantes en el discurso jurídico. Imputar la condición de «racional»o «razonable»a discursos como esos mismos —o sea, sin parar para nada mientes en papel central que allí desempeña el Síndrome- no significa sino acorazarlos con unas denominaciones persuasivas que, valiéndose del sentido emotivo de dichos términos, de hecho brindan una mampara más para que tales discursos sean mantenidos esencialmente así como ya son. Vale decir que esa pseudo-«racionalidad» va dirigida, de hecho, contra la introducción de modos de razonamiento menos falaciosos (i.e., anti-Síndrome) ${ }^{39} \mathrm{y}$ en general que sean tomados en cuenta unos conocimientos básicos de las ciencias sociales, para alcanzar respuestas realistas en el campo de los razonamientos prácticos, en vez de llamarse a conforme allí con unas «razonabilidades» simplemente «argumentativas»... De hecho se trata, en definitiva, de una «estrategia de inmunización» (ALBERT) ${ }^{40}$ para defender la permanencia de un pensamiento de carácter pre-científico, el tradicional, en ese terreno.

Ello tiene que ver, por lo demás, con cierta indefinición en que PERELMAN deja lo que se refiere a las relaciones entre retórica y verdad. Por un lado, nos dice que «lo que distingue a la retórica de la lógica formal o incluso de las ciencias positivas es que aquella [la primera] no concierne tanto a la verdad como a la adhesión» ${ }^{41}$. Por el otro, señala que solo «en ciertos casos, que por cierto son excepcionales, se dará preferencia (en la argumentación) a otros valores que la verdad» ${ }^{42}$.

De ese planteamiento no se sigue con nitidez si el único (suficiente) o principal criterio de verdad con respecto a un razonamiento práctico sería: 1) la adhesión que le preste un auditorio; o bien si, en cambio, 2) la calificación del auditorio mismo haya de medirse en función de parámetros de la verdad que lo trascienden ( $¿ E s$ que el «auditorio universal» vendría a significar, acaso, algo así como una «idea» en sentido

36 Vid. 1977, 1990 (esp. $\$ \$$ IV-V y VIII-X), 2006a (sec. B. I, esp. \$\$ 5 y 8).

37 Cfr. los sitios indicados supra, nota 34.

38 Cfr. 2006a, B.I.3-4.

39 Cfr. 2006a, sec. C.III.1.

40 Cfr. H. AlBeRT, Tratado sobre la razón crítica (trad. R. Gutiérrez Girardot), Buenos Aires, 1973; y Ética y metaética (intr. J. Rodríguez Marín, trad. M. Jiménez Redondo), Valencia (Esp.), 1978.

41 Perelman, op. cit. (ref. supra, nota 28), 1978, 141.

42 Op. cit. (ref. supra, nota 28), 153. 
kantiano?) ${ }^{43}$. Sea como fuere, solo la primera de esas dos posibilidades es capaz de imponerse en la práctica si se acepta el ideal que para los razonamientos prácticos pregona la nouvelle rhétorique. Basta con que el auditorio de juristas esté integrado - como es habitual - por personas poco versadas en razonamientos científicos propiamente dichos, y por lo demás sujetas al Basic Legal Myth ${ }^{44}$, para que así queden legitimadas, sin posibilidades de apelación ante otras instancias del conocimiento, las formas tradicionales de pensar que dominan en el discurso jurídico: ¡normativismo! También por este lado, pues, esta posición de PERELMAN se revela como una defensa del pensamiento poco («débilmente») científico para el Derecho, una ideología de lo «razonable» contra la racionalidad propiamente científico-empírica.

\section{INCERTIDUMBRE Y MANIPULABILIDAD DE LO QUE ES LLAMADO «RAZONABLE»}

El alto grado de incertidumbre que es propio de lo llamado «razonable» queda en evidencia ya con la caracterización dada por el propio ARISTÓTELES para esa forma de pensamiento. Él señaló una serie de instancias, los «círculos» (llamémosle así) de autoridades invocadas que ostentan legitimación para dictaminar sobre la probabilidad —más general: la plausibilidad — de las proposiciones en cuestión:

«Silogismo dialéctico es aquel que obtiene su conclusión de proposiciones simplemente probables» (Tópica, Libro I, cap. I.5). «Llamamos probable a lo que tal parece [a las autoridades siguientes], ya a los sabios, y, entre éstos, a todos o a su mayor parte, ya a los más ilustres y más dignos de crédito» ${ }^{45}$.

Empero, como esas autoridades son de naturaleza muy diversa, resulta que, en la práctica, los resultados pueden ser distintos según cuáles de dichas instancias se prefiera tomar en cuenta; más aún, según cómo se determine quiénes son los individuos concretos llamados a hablar en nombre de la especie de autoridad interrogada. Por ejemplo:

«"Lo que todos tienen por justo" significa, si le buscamos posibles traducciones: la voluntad del pueblo, la volonté de tous, la convicción jurídica general, las leyes vigentes. Lo que la mayoría considera justo puede querer decir: la mayoría a través de votaciones, la opinión pública, la clase llamada a ser la dirigente, todas las personas de pensamiento justo y equitativo, la ley que ha sido producida en forma democrática, la opinión dominante en la doctrina y en la jurisprudencia. Como "sabios" para protagonizar la argumentación, pueden ser tomados en cuenta: desde el punto de vista político, la clase dominante, el presidente Mao (o Fidel Castro o Chávez), el líder (Fübrer) cuya voluntad es creadora de Derecho; de manera general, los hombres de ciencia; desde el punto de vista jurídico, el Tribunal Constitucional Federal, los tribunales en general, los profesores de Derecho» ${ }^{46}$.

${ }^{43}$ Vid. op. cit. (ref. supra, nota 28), $\$ 52$.

${ }_{44}$ Cfr. J. Frank, Law and the Modern Mind, Gloucester (Mass.) [ed. or. 1930, ed. ampl. 1949], 1970. Para una síntesis en español de las ideas fundamentales de ese autor al respecto, puede verse 2006a, sec. C.I.2.

${ }_{45}$ ArIstóteles, Tópica; en Obras Completas. Lógica III, Madrid, Nueva Biblioteca Filosófica (vol. XLVII), 1931, cap. I.8.

46 N. HoRn, «Rationalität und Autorität in der juristischen Argumentation», Rechtstheorie, vol. 6/2, 1975, 145-160, 148 y ss. Mi comentario crítico: 1977. 
Es evidente que con bases tan variadas y generalmente inciertas, por lo habitual no será posible alcanzar ningún grado firme de intersubjetividad. Ni siquiera se conseguiría si fuera fijado, de alguna manera, un determinado círculo de referencia — quiénes son los que contarán como «sabios» o como «expertos»— limitándolo a una sola de las instancias señaladas: por ejemplo, a los juristas profesionales o a un sector especializado de éstos (tribunales de justicia o profesores de la Facultad de Derecho). Aun así la cuestión de la intersubjetividad no quedaría resuelta, pues las discrepancias se plantean, de todos modos, en el interior mismo de dicho círculo, tal y como puede observarse en cuanto al Derecho.

Las dificultades para determinar qué sea lo verdaderamente «razonable», llegado el caso, no tienen solo que ver con el hecho de que no se sepa bien cuál es concretamente la composición del círculo de referencia: ¿«auditorio universal»o algún sector más restringido de personas? La dificultad es inmanente al fondo mismo del asunto, puesto que, por definición, estamos ante lo «razonable» cuando, justamente, faltan criterios unívocos, sea cual fuere el círculo de referencia, para resolver las cuestiones en consideración. Si tales criterios estuvieran allí disponibles, no diríamos que se debe resolver esos asuntos de alguna manera «razonable», sino que los solucionaríamos acudiendo a tales o cuales pautas netamente intersubjetivas.

Por lo demás, con respecto a ese carácter de «diálogo» que se reivindica para el Derecho como discurso razonable, es muy pertinente la observación de COURTIS:

«No es difícil imaginar el proceso judicial como un diálogo. Pero asumida esta metáfora, cabe cuestionarse acerca de los sujetos del diálogo, su objeto, el lenguaje utilizado, el contexto en el que se produce, las reglas que lo rigen, la situación de jerarquía entre los sujetos» ${ }^{47}$.

En efecto, toda la cuestión reside en saber cómo tienen lugar tales «diálogos» argumentativos. Lo interesante es ver si lo sostenido en ellos son unos conocimientos intersubjetivos, como los de las ciencias en general, o si, al contrario, ello varía de acuerdo con las respectivas preferencias - las ideológicas y demás_- de cada dialogante. También importa averiguar de qué depende, en realidad, que estos mismos tengan ahí unas $\mathrm{u}$ otras entre tales preferencias. Todas estas preguntas son, justamente, aquellas de las que no suelen ocuparse los apologetas del pensamiento «razonable».

\section{ESAS TEORÍAS SOBRE LA ARGUMENTACIÓN JURÍDICA CONSTITUYEN SOBRE TODO UNA MODALIDAD DE PRÉDICA, NO SON UNA EXPLICACIÓN EMPÍRICO-CIENTÍFICA}

Supongamos que la teoría sostenida por una escuela de sociólogos o de psicólogos afirmara que Los Diez Mandamientos son las estructuras mentales básicas a que se ajustan las decisiones tomadas por los políticos y para las conductas normales de la gente en general. Desde luego, tal teoría no existe (al menos en el medio académico), por la sencilla razón de que en las ciencias sociales se tiene bien claro la diferencia

47 C. CourTis, «Estrategia de nuestra araña. Una visión crítica del Derecho y del rol del abogado desde perspectivas contemporáneas», en AA.VV. (dir. J. F. Palomino Manchego), Discusión sobre el carácter anticientífico del Derecho, Lima, 1999, 253-270: 263. 
categorial entre dos tipos de discursos: el de la prédica religiosa y el de la explicación científica.

La prédica religiosa tiene su propia legitimidad, siempre y cuando aquélla sea entendida como lo que verdaderamente es. Dichos Mandamientos son exhortaciones, basadas en unas creencias de valores, pero es patente que las personas suelen pasar por encima de aquéllas en la práctica. Se invocan de palabra, llegado el caso, pero: ¡del dicho al hecho...! Los científicos sociales, en cambio, pretenden dar cuenta sobre cómo la gente actúa en la realidad. Por eso, ellos no postulan una regularidad -leyes sociológicas o tendencias estadísticas de grupos- en los comportamientos sociales que coincida con el contenido de esos Mandamientos. Las elucidaciones y las exhortaciones con respecto a estos mismos, o a otros principios éticos, son cuestiones que para nada se confunden con cómo son las conductas sociales en sí mismas.

Análogamente, en cuanto al Derecho: una cosa es predicar ciertos ideales sobre cómo debieran razonar sus locutores profesionales, muy otra cosa es describir cómo sus discursos son de hecho. Sin embargo, la abrumadora mayoría de lo que hoy por hoy se presenta en la disciplina denominada Teoría del Derecho aparta la vista de semejante diferencia fundamental. No se pone atención a distinguir entre la prédica de ciertos principios de racionalidad o razonabilidad y el averiguar en qué medida sea comprobable empíricamente (verificaciones y falsaciones) cómo tales principios se lleven a la práctica - io no! - en la labor jurídica normal. En esos estudios se trata, por lo general, de tales o cuales formas ideales de razonamiento: los destacados por unas $\mathrm{u}$ otras tendencias que, cada una por su lado, pueblan los estudios de dicha disciplina. Por añadidura, generalmente esas tendencias se encarnan en grupos de académicos dogmáticamente cerrados, sus miembros no dialogan más que entre sí mismos, no aceptan entrar en discusión pública con quienes presenten razones radicalmente críticas frente a sus dogmas epistemológicos básicos.

Bajo el membrete «Teoría de la Argumentación» se ubica una de las corrientes que están en boga en esa disciplina. A pesar de existir sensibles diferencias de orientación, hasta netas contradicciones, entre esta última y otras aproximaciones teoréticas en la materia — p. ej., frente a la «rigurosidad» cientificista de unos complejos lógico-deónticos o la putativa cientificidad de unas teorías formulistas de sistemas-, los estudios de Teoría de la Argumentación jurídica comparten con casi todas las demás tendencias que están ahí de moda el escapismo básico, esto es: a) apartar la vista de las celadas retóricas dominantes en los discursos jurídicos reales (Síndrome), y b) disimular la diferencia clave entre law in books y law in action (POUND, LLEWELLYN) ${ }^{48}$.

En efecto, la visión que sobre el razonamiento jurídico ofrecen aquellos connotados teóricos actuales - y en general quienes siguen su ejemplo- que lo encaran como modelos de «argumentación» monta la siguiente confusión básica: hacer pasar como si estos modelos en sí mismos fueran un «es» — plano descriptivo—, pero a fin de cuentas constituyen más que nada ciertos buenos consejos de «debe»—plano prescriptivo- abstraídos con la mente puesta en unos juristas ideales. Si acaso esta diferencia sustancial aparece mencionada en alguna página de tales estudios, queda diluida a lo largo de la mayor parte de los desarrollos allí presentados, pues casi todos estos

${ }^{48}$ Cfr. Llewellyn, op. cit. (ref. supra, nota 13). 
mismos permanecen consagrados simplemente a unos «debe» argumentativos. Tales modos de argumentar no tienen que ver sino lejanamente, o en todo caso de modo sólo muy parcial, con las maneras habituales en que los profesionales del Derecho elaboran sus discursos para la práctica cotidiana de sus actividades en la materia. Ello ha sido abundantemente comprobado en estudios de autores no complacientes con la «lógica» propia de dichos discursos ( $c f r$. H. Kantorowicz, J. Frank, W. Scheuerle, R. LaUtMANN, G. TARELlO, P. GOODRiCH, A. NiETO, etc.), exámenes acerca de los cuales esos teóricos se contentan con «no chistar palabra». No menos puede darse cuenta de ello cualquier juez y cualquier abogado inmersos en esa práctica misma, si por algún azar se preocupasen en tomar conocimiento de estudios como los de aquellos teóricos y cotejarla con las sutilezas pergeñadas en estos últimos.

Las teorizaciones «argumentativistas» se concentran en ciertos aspectos de la semántica utilizada para los discursos en cuestión, mas hacen abstracción de la pragmática lingüística correspondiente. Puesto en las categorías de WitTGEnSTEIn: no se ocupan de las proteicas «gramáticas» — semántica real: Síndrome, etc.— a que responden los «juegos de lenguaje» jurídicos efectivos. En lugar de estos mismos, en esos estudios lo que aparece son unas formas idealizadas, como asimismo ellos dejan completamente fuera de foco en qué formas de vida — conductas efectivas en los tribunales y cuáles son sus efectos de hecho- se traducen dichos juegos en la práctica. Esos autores se preocupan de cómo intercambiar argumentos en el «cielo», haciendo a un lado cómo funcionan las argumentaciones de la «tierra» (JHERING).

A diferencia de los discursos con que nos encontramos todos los días en los tribunales y en la dogmática jurídica enseñada por parte de las cátedras universitarias, los razonamientos que manejan aquellos juristas ideales de que se ocupan las teorías de la argumentación jurídica son presentados como si no estuvieran anclados a los ítems típicos del Síndrome y a las dinámicas sociales efectivas. Por lo que se ve, esas teorías no consideran del caso poner el acento sobre la presencia constante de semejantes ítems —unos u otros- en los razonamientos jurídicos normales. Ninguno de los (14) «rasgos característicos» ${ }^{49}$ de los exámenes que ofrecen los principales autores de dichas teorías se fija en tal Síndrome, por lo cual hube de señalar esa omisión como decisivo rasgo adicional (15). Este último resulta absolutamente clave para separar tales visiones acerca del pensamiento jurídico (ideal) frente a las prácticas de razonamiento que predominan de manera efectiva en la ciencia jurídica normal ${ }^{50}$.

En efecto, el rasgo común más decisivo de las teorías «estándar» sobre la argumentación jurídica es ese último, el quinceavo: japartar la mirada del Síndrome en las argumentaciones del Derecho usadas en los tribunales y en la enseñanza profesional de esta disciplina! Sí, míreselas por donde se las mire, estas teorías de la argumentación pasan olímpicamente por encima de aclarar dónde, cuándo y cómo los razonamientos jurídicos dejen de lado, en la práctica, recurrir a dicho Síndrome. En eso, por encima de cualesquiera diferencias entre sus respectivos planteamientos particulares, se anuda la comunión intelectual que los autores volcados al racio-argumentativismo mantienen

49 Supra, a la altura de la nota 14.

50 Vid. 2011a, passim. 
entre sí, todos ellos: esto es, su vocación básica de hacer caso omiso de, justamente, cuanto sea poner al desnudo el carácter predominantemente «celestial» de esas aproximaciones en general.

O bien, no sé si del prudente silencio que ellas suelen guardar al respecto (en el mejor de los casos, llegan a reconocer algo de ello apenas de paso) ${ }^{51}$ habrá que extraer una de las dos conclusiones siguientes: ya sea que dicho Síndrome no exista ahí, ya sea que él afecte en muy poco o nada a la «razonabilidad» de las argumentaciones jurídicas enhebradas con él. Ambas conclusiones, si es que esos autores piensan así [ $\dot{c}$ ?] y hasta se animaran a sostenerlas abiertamente, no son nada difíciles de someter a verificación empírica, supuesto que alguno de ellos estuviera dispuesto a afrontar tal riesgo. Bastaría con examinar atentamente una o dos resoluciones de tribunales superiores (elegidas por parte del propio teórico «argumentativista») en donde se haya resuelto una cuestión muy discutida, con votos divididos. Sería cuestión de verificar, ahí mismo, si es verdad que en la fundamentación puesta no se hacen valer unos ítems del Síndrome, o sea, que ninguno de éstos hubiere sido invocados allí como decisivo para arribar a la sentencia en cuestión. No estoy enterado de que alguno de los teóricos más conocidos de dicha corriente, ni sus discípulos, haya consentido en someterse a tal prueba ${ }^{52}$. Eso sí, tendría que ser para efectuar el debate no simplemente entre ellos mismos, o frente a unos reparos externos no demasiado «incómodos», sino en discusión abierta con unos críticos no contemporizadores, vale decir, de orientación netamente realista. Debate en el que no están para nada interesados, por cuanto se ve ${ }^{53}$.

En definitiva: A no ser que los contenidos del Síndrome sean un invento de unos comentaristas meramente «molestones», o que los ítems de aquél se presentaran ape-

51 Es algo así como cuando en un periódico se deja constancia de una aclaración incómoda, pero confinándola en alguna página muy secundaria y puesto en letra pequeña.

52 Incluso me he ofrecido yo mismo para realizar con cualquiera de ellos tal prueba, sin obtener respuesta (que yo sepa). En esta misma Revista, donde se ha discutido y rediscutido, una y otra vez, los puntos de vista de autores como DWORKIN y ALEXY, nadie ha tomado el guante frente a razones radicalmente opuestas a las de éstos: no asoman sino unas objeciones muy secundarias, las cuales son apenas de detalles, todas ellas esencialmente reverenciales ante esos autores (así en Doxa, núm. 26, 2003, 145-238, estudios con respecto a ALEXY). Hasta puedo señalar como ejemplo, de tal silencio, el hecho de que no hayan sido objeto de réplicas (que yo sepa) ni una sola de las razones concretas — ide fondo! - que he presentado (documentadamente) con respecto a las falacias claves en que se basan los desarrollos de esos autores: $c f r .1998$ y 2001a. Por supuesto, es muy posible que razones similares, o hasta más fuertes, se encuentren expuestas ya desde antes, en otros sitios; pero también ellas, sea como sea, han corrido con no mejor suerte. Vid. también infra, notas 53, 72, 76 y 79.

53 Por cierto, la actitud mental hoy dominante es de inclinación a priori frente a cualquier escritor de buen marketing (efecto-Vicente: $c f r$. 2001a, $\mathbb{2}$ 2). Esa autocensura intelectual —vale decir, pre-establecidaque marca la tónica en la literatura secundaria acerca de aquéllos no es cosa privativa de la corriente pro«argumentativista», por cuanto hace a la indisposición de confrontarse abiertamente con unas críticas «impías» (si las hay) de las opiniones reverenciadas. Lo mismo caracteriza de manera general a los trabajos sobre las demás orientaciones dominantes en la actual Teoría del Derecho: p. ej., pasa también con respecto a las elucubraciones de RAWLS o las de FERRAJOLI [así, el número de Doxa (31-2008) está consagrado centralmente (207433) a aplaudir — ino a someter a una discusión en sentido propio! — la obra más reciente de este último (cfr. supra, nota 3). Si bien ahí se ofrece un conjunto de análisis en relación con ésta, todos ellos son esencialmente reverenciales; no se encuentra ningún examen que contenga críticas a fondo —esto es, propiamente analíticorealistas - acerca de las novelas de conceptos en cuyas tramas se mueven primordialmente los planteamientos de ese autor. Mas tengo entendido que el profesor M. E. SALAS tratará de dar a conocer un estudio, «Derecho y sin-Razón», en donde, justamente, se coloca sobre el tapete lo que en aquellos otros exámenes queda complacidamente fuera de foco]. 
nas por excepción o en todo caso sin influencia práctica decisiva en la configuración del razonamiento jurídico normal, después de todo la ejemplar «racionalidad»o «razonabilidad» que caracteriza a las argumentaciones de los juristas viene a consistir, de becho, inclusive en dejarse guiar por dicho Síndrome. Así resulta que también la «racionalidad argumentativa» de las propias teorías «estándar», ellas mismas, consiste en contribuir a santificar, mediante este legitimador silencio suyo al respecto (mejor es no meneallo... ${ }^{54}$, la intervención de este Síndrome como guía teorética efectiva en los desempeños de los operadores jurídicos reales.

[III]

«RACIONALIDAD» COMO EXPEDIENTE PARA TEORIZACIONES ESCAPISTAS

«The finer and more accurate the processes of political science become, the less do they count in politics».

G. WALLAS 55

\section{7. «RACIONALIDAD» $\mathrm{O}$ «RAZONABILIDAD» FANTASIOSAS, EN LA ACTUAL TEORÍA DEL DERECHO (Y LA FALACIA INTELECTUALISTA) ${ }^{56}$}

Los autores de teorías «estándar» acerca de la argumentación jurídica se esfuerzan por destilar ciertos conjuntos, más o menos complejos, de pautas «razonables» que, según suponen ellos, pueden y deben servir para solucionar de la mejor manera los problemas prácticos a que se enfrentan los juristas. Claro que la pretensión de ofrecer unas u otras modalidades de «racionalidad» (imaginaria) no es privativa de dichas teorías. En cuanto a partir de semejante pre-concepción, muy general, éstas se dan la mano con variadas otras tendencias que están de moda en la Teoría del Derecho. En efecto, tanto la fórmula de fantasía que ha hecho circular RAWLS ${ }^{57}$, la mélange de trivialidades y confusionismos puestos sobre la mesa por DwORKIN ${ }^{58}$, múltiples juegos de esquemitas del cientificismo lógico-deóntico ${ }^{59}$ (p. ej., esas siderales axiomatizaciones inventadas por FERRAJOLI, hazañas en componer jerigonza «sistémica» o la de la semántica estructural, más tantos otros escapismos pseudo-«técnicos» —no sólo los disimuladores alambicamientos presentados como procedimientos de «ponderación»—) ${ }^{60}:$ ¡todas esas vías pretenden ser ni más ni menos que bien «racionales» o «razonables»!

54 Vid. 2011a, cap. IV.10.d («Lo que no se acepta debatir»).

55 G. Wallas, Human Nature in Politics, University of Nebraska Press [la ed. orig. es de 1908; la 3. . ed., 1920, añade un prefacio del autor; en ediciones posteriores, a partir de 1948, se incorpora un Foreword de A. L. Rowse], 1962, 186. La cita de Rowse ubicada al comienzo de este artículo se encuentra en la p. 2 de dicho libro (negr. e.p.h.).

${ }_{56}$ Para desarrollos más amplios sobre este punto: 1996c.

57 Vid. 2009b o 2010b (cap. V).

58 Vid. 2001a o 2009a.

59 Vid. 1996a o 2003 (cap. VIII).

${ }^{60}$ Cfr. García Amado, op. cit. (ref. supra, nota 3). 
El punto-eje en que cada una de esas teorías — no sólo las «argumentativistas»dan su salto hacia el «cielo» es el siguiente (voy a citar un autor cuyo apabullante estudio empírico jamás es mencionado — ¡no es difícil entender por qué! — en dichos trabajos):

«El ideal de la racionalidad excede (überfordert), por muchos motivos, las posibilidades de un decisor como el juez. La verdad, corrección y completud no van a constituir, presumiblemente, los únicos criterios para su actividad; dicho con más exactitud, la construcción de la verdad en los procedimientos profesionales de decisión (judiciales) persigue menos una racionalidad utópica (p. ej., tipo RAWLS o HABERMAS-ALEXY), que una racionalidad limitada definida socialmente. Las dimensiones de ésta no se determinan sólo con unos medios lógico-analíticos (como la teoría normativa de la decisión, la teoría de los juegos, etc.). Los principios de construcción de una verdad que es aceptada como verdad por parte de una sociedad determinada han de describirse por los medios de las ciencias empírico-sociales» ${ }^{61}$.

Estos «principios», los que comandan realmente el pensamiento social —vale decir, no los de la dogmática jurídica y en general los presentados por las aproximaciones racionalistas en Teoría del Derecho- no son algo capaz de ser «construido», para la práctica, con base en imaginerías como, entre otras, una «situación de habla ideal» (HABERMAS) o una «posición original» (RAWLS) o unos razonamientos axiomatizados (cualesquiera sean: p. ej., FERRAJOLI) y las formulitas lógico-deónticas en general (p. ej., ALCHOURRÓN y BULYGIN).

Semejantes idealizaciones dan por admitida una predominancia neta de ese factor, esencialmente intelectual, que llaman lo «racional» o lo «razonable» en el pensamiento de los juristas. Bien representativo de tales tendencias es el conocido libro de AlEXY (1989) sobre «argumentación jurídica» ${ }^{62}$, obra que sigue siendo corrientemente señalada como punto de referencia al respecto. Allí ese autor termina proponiendo, a partir de la leyenda consistente en una «situación ideal de dialogo» (HABERMAS), toda una compleja «tabla de las reglas y formas» para llevar a cabo «razonablemente» el discurso jurídico ${ }^{63}$. Planteamientos como los de AlEXY, si bien no están desprovistos de fineza, y por tanto no dejan de ofrecer cierto interés teorético, empero llevan por caminos que, en definitiva, tienen más bien poco que ver con las prácticas discursivas cultivadas por los profesionales del Derecho.

Al fin de cuentas, tal orden de teorizaciones no constituye sino otras manifestaciones más - ientre tantas que circulan por ahí! - de lo que bien puede calificarse como falacia intelectualista. Se trata, en sustancia, de aquello que a comienzos del siglo pasado (1908) Wallas supo bien reconocer llamándole «the intellectualist assumption», esto es:

«... what may conveniently be described as the Rationalist Fallacy in political thinking: namely the assumption that buman beings largely act in politics ( $\mathrm{y}$ en general en sus conductas

${ }_{61}$ R. Lautmann, Justiz - die stille Gewalt, Francfort, 1972, 21 y ss. (negr. e.p.h.).

62 R. Alexy, Teoría de la argumentación jurídica (trad. M. Atienza e I. Espejo), Madrid, 1989. Examen crítico: 1998.

${ }_{63}$ Cfr. el resumen en dicho libro, op. cit. (ref. supra, nota 62), 283 y ss. Ese mismo autor ha puesto especial énfasis, más adelante, en un sofisticado procedimiento de disimulaciones para efectuar la «ponderación» de principios del Derecho constitucional, con vistas a la solución de casos en donde pueda haber conflicto entre aquellos [cfr. GARCía AMADO (ref. supra, nota 3)]. 
sociales —así también proceden como juristas-) upon rational motives and trains of intelligent reasoning. We in our time, alas, know what fatuous nonsense this is».

De ahí que:

«... nearly all students of politics (o de Derecho) analyse institutions and avoid the analysis of man».

Y es así como, al fin de cuentas:

«... many of the more systematic books by American university professors (e igualmente los de otros países) are useless, just because the writers deal whit abstract men (joh!, RAWLS, HABERMAS, AlEXY, FerRAJOLI...), formed on assumptions of which they were unaware and which they had never tested either by experience or by study» ${ }^{64}$.

Quiéranlo o no tales autores, su laboriosa presentación en cuanto a racionalidad o razonabilidad de los discursos jurídicos — así dicha «situación de habla ideal» y los rebuscados procedimientos de «ponderación»— resulta inocua como propuesta metodológica para incidir en las resoluciones prácticas. Salvo para alambicar unas fachadas de presentación, que permitan hacer pasar como si fueran algo meramente técnicoobjetivo las opciones valorativas decididas por el propio intérprete ${ }^{65}$, las cuales no pueden sino ser contingentes. La práctica del Derecho consiste en unos discursos bastante poco «ideales»: ciencia jurídica normal. En comparación con estos mismos, aquellas presentaciones —una ciencia jurídica exquisita — ${ }^{66}$ pasan a fungir, sobre todo, como expediente profesoral de maquillajes idealizadores frente a lo que son los discursos efectivos de los juristas profesionales en general ${ }^{67}$. Esa vis escapista, señaladamente disimuladora, que por lo general conllevan los estudios dedicados a poner de manifiesto la «racionalidad» o «razonabilidad» de los discursos jurídicos, mediante dichas presentaciones «argumentativistas» sobre los razonamientos de los juristas, brinda una vía singularmente sugestiva para legitimar que se aparte la vista de la «tierra» de que se compone y donde se mueven los desempeños discursivos de estos mismos en la práctica.

Casi todos los que escriben estudios al respecto, en cualquiera de las variadas direcciones teoréticas existentes en el seno de la disciplina Teoría del Derecho, tienden a contemplar el pensamiento jurídico como manifestación, sea en unas u otras formas, del paradigma fundamental constituido por una gran ficción general básica: la idea de que ese pensamiento está determinado por, o en todo caso ha de ser reconstruido como, una estructura del tipo «sistema jurídico». Si bien el orden de líneas fundamentales que ordenan tal sistema no son las mismas según unos y otros autores, dicha idea suele resultar bastante engañadora para aprehender cómo el Derecho funciona de

${ }^{64}$ Las tres citas se toman de WALLAS, op. cit. (ref. supra, nota 55): la primera son palabras de ROWSE (1 y ss.), las otras dos pertenecen a WALLAS mismo (37 y 38 ) [curs. e.p.h.].

65 Vid. el sitio indicado al final de la nota 63.

66 Desvelar el radical desfase existente entre ciencia jurídica «normal» (los discursos jurídicos corrientes) y ciencia jurídica «exquisita» (meta-Teoría del Derecho) es el propósito central de mi 2011a.

67 Así, la teorización idealista «estándar» ofrecida por ALEXY es paradigmática de la vis escapista que por lo general conllevan los estudios dedicados a poner de manifiesto la «racionalidad» o «razonabilidad» de los discursos jurídicos. Esa gran clase de orientaciones, esencialmente disimuladoras, se asienta sobre todo en seis rasgos básicos $(a-f)$ que he señalado en 2006a, 352 y ss. 
veras. Sea cual fuere el «sistema» presentado, se trata de una visión sustancialmente intelectualista acerca de lo que es —así se supone- el pensamiento jurídico.

Claro está que toda teoría es, y no puede sino ser, un producto intelectual, sea cual fuere el grado de acierto o desacierto de cuanto en ella se diga. Señalar que una idea tiene naturaleza «intelectual», en principio constituye una calificación simplemente descriptiva, avalorativa. En cambio, la palabra «intelectualista» conlleva cierta connotación peyorativa: no se aplica a cualquier conducta intelectual, sino a unas que se tenga por poco recomendables. Así, en el caso que nos ocupa, el «pecado» no reside en examinar intelectualmente los fenómenos jurídicos, sino en hacerlo de una manera ficcionalizante. Ésta consiste en partir como base del prejuicio profesoral de que esos fenómenos en sí mismos se rigen necesariamente por los mismos gustos - esprit de géométrie - a los cuales para «construir» sus discursos académicos se afilian las teorizaciones racionalistas, sean de unas u otras escuelas («razonabilistas», «sistémicos», «estructuralistas», logicistas en general). Es verdad que también los enfoques realistas constituyen unas aproximaciones intelectuales, mas ellas procuran, antes que nada, saber precaverse justamente de las confusiones intelectualistas, esto es: se cuidan mucho de no ceder a la tentación de tener por «intelectualizada» a la propia realidad social en examen (p. ej., la de aquellos hábitos mentales que los juristas tienen de hecho y practican de hecho) ${ }^{68}$.

EN SÍNTESIS: Esa visión que es fundamentalmente intelectualista, producto de la fantasía lingüística enraizada en ciertos tipos de discursos con que se ejercita el quehacer académico, significa una suerte de ombliguismo profesoral. La verdad es que en los razonamientos reales de los juristas se abre paso, quiérase o no, una señalable cuotaparte de extra-sistematicidad. Nos guste o no nos guste, esos razonamientos no dejan de responder, en aspectos bien decisivos, a una serie de elementos que son básicamente no-racionales, o hasta anti-racionales (Síndrome y demás).

\section{DISCUSIÓN: ¿NO ES CIERTO QUE DICHAS TEORIZACIONES («ESTÁNDAR») DISIMULAN EL DECISIVO PAPEL QUE EN LAS ARGUMENTACIONES JURÍDICAS JUEGAN EL SÍNDROME NORMATIVISTA Y LOS CONDICIONAMIENTOS SOCIETALES EFECTIVOS?}

He insistido en subrayar aquello de lo cual las teorías «estándar» sobre la argumentación jurídica prefieren no hablar; y he dicho que, por eso mismo, tal orden de teorizaciones son ni más ni menos que un expediente de disimulación («embellecimiento» ideológico, «cirugía estética») con respecto a los razonamientos jurídicos reales. Ahora bien, ¿no será ésta una afirmación injusta, o de todos modos bastante exagerada?

Podría acaso replicarse que nadie está obligado, y por lo demás es imposible, hablar de todo al mismo tiempo; ni siquiera de absolutamente todo lo que efectivamen-

68 Cfr., sobre todo, los estudios de SCHEUERLE (ref. infra, nota 90) y el de LAUTMANN [op. cit. (ref. supra, nota 61)]. 
te resulte decisivo para ocasionar cierta especie de efectos en particular. Desde luego, la división en especialidades científicas no es sino el resultado de tal imposibilidad: p. ej., ¿por qué un cardiólogo, al examinar a su paciente, debería también señalar todo lo que sea capaz de ver con respecto a este mismo un dermatólogo? Análogamente, los especialistas en Teoría de la Argumentación no se ve por qué vengan a «disimular» algo, por el simple hecho de no ocuparse ellos mismos de otros elementos de un resultado global, aun cuando ciertamente jueguen también éstos su papel para establecer causas efectivas y consecuencias efectivas de unas argumentaciones. No es lo mismo, se dirá, «negar» o «esconder» tales o cuales aspectos en cuanto a los razonamientos jurídicos — sus condiciones no específicamente «argumentativas»que simplemente remitir el estudio de esos otros aspectos a exámenes por parte de otros especialistas. Para seguir con el mismo ejemplo, mutatis mutandis. el cardiólogo no «disimula» las impurezas que tenga el cutis del paciente, simplemente le dice a éste que si quiere saber de eso otro vaya a preguntarle al dermatólogo.

Una justificación por el estilo, frente a los silencios de los teóricos de la argumentación jurídica, se desprende de una caracterización como la siguiente ${ }^{69}$ :

«... me ocuparé, concretamente, de la argumentación jurídica y en especial de la argumentación judicial ${ }^{70}$, cuyo objeto es el "razonamiento justificativo" que realizan los jueces "a favor del carácter correcto o aceptable de sus decisiones" y no, como aclara M. ATIENZA, "las razones que permitirían explicar (a través de un estudio de tipo psicológico, sociológico, ideológico, etc.) esas decisiones" ${ }^{71}$.

Ahora bien, todo el asunto es: ¿qué nos permiten saber de veras semejantes estudios, puesto que responden a los pre-supuestos esenciales de la teoría «estándar» (supra, $\$ 2$ )? Si este «qué» se entiende referido a los razonamientos jurídicos reales, la cuestión no es solamente que dichos estudios no orientan para nada en ponerle atención a los factores «de tipo psicológico, sociológico, ideológico, etc.» que allí entran en juego decisivamente. Es más, ni siquiera conducen a tomar conciencia de elementos fundamentales que suelen integrar el propio «razonamiento justificativo» como tal, esto es: el Síndrome y las celadas lingüísticas en general, allí presentes una y otra vez. Ese Síndrome no es, por cierto, algo «externo» (por decir así) al propio «razonamiento justificativo», pues constituye, de hecho, el meollo básico en muchos de esos razonamientos en la práctica jurídica profesional — isean cuales fueren sus determinantes «de tipo psicológico, sociológico, ideológico, etc.»!- ¿ ¿Por qué los teóricos «argumentativistas» hacen abstracción de eso mismo — ¡no sólo de aquellos otros determinantes! - a pesar de existir material abundantísimo al respecto en el «razonamiento justificativo» mismo llevado a cabo en los tribunales? ¿Por qué en esos estudios no es dable encontrar prácticamente nada de, por ejemplo, la variada lista de argumentos reales consignados por SCHEUERLE? (No se le busque excusa alegando que este último autor es prácticamente un desconocido afuera de Alemania, puesto que: a) nada menos que un autor tan importante como ALEXY no puede alegar tal ignorancia ${ }^{72} ; b$ ) por

${ }_{69}$ M. N. Febres Siso (17 de abril de 2008): «Argumentación y sentencia», texto en Internet. Las dos notas que siguen se recogen de dicho texto.

${ }_{70}$ ATIENZA. op. cit. (ref. supra, nota 14), 11 [nota 4 de Febres Siso, loc. cit. (ref. supra, nota 69)].

${ }^{71}$ Febres SisO, loc. cit., nota 5 del autor.

72 Es más, yo mismo lo hice ver en un sitio que él no desconoce (1996b: $\$$ VI, esp. 318-320) (su manuscrito lo tuvo antes ALEXY en sus propias manos) y después lo traduje al español (1998). Hasta donde estoy 
lo demás, ¿a qué se debe el misterio de que tampoco los teóricos «argumentativistas» de otros países hayan llegado a percibir, en sus propios medios, «celadas» argumentativas parecidas a las detectadas por SCHEUERLE, y otras, que también en esos medios jurídicos no son nada raras?).

Por lo demás, según vimos, los estudios «estándar» sobre argumentación jurídica se concentran sobre todo en elucidar unas racionalidades o «razonabilidades» ideales. Pero en esas teorías de la argumentación no es efectuada nítidamente la distinción entre argumentaciones jurídicas reales (las llevadas a cabo en los tribunales) y argumentaciones jurídicas ideales (unas formas propuestas por los autores de dichos estudios) (supra, $\mathbb{2}$ ). Al contrario, tales teorías pretenden describir la «argumentación judicial» misma (véase la cita correspondiente a la n. 71), mas la presentan bajo la máscara («cirugía estética») 73 que pone a la argumentación ideal como si fuera en general más o menos lo mismo que las fundamentaciones jurídicas reales.

Cada quien, también un grupo de investigadores, puede interesarse en aquello que mejor le plazca, claro está. Los intereses intelectuales no dejan de ser, al fin de cuentas, unas cuestiones de «gustos». Hay gustos, de ésos, que pueden llegar a provocar unas aplicaciones tecnológicas; otros, no. Lo que de acertado tengan unos conocimientos científicos, o los filosóficos, no depende necesariamente de si sean capaces de producir efectivamente ciertas consecuencias prácticas, sino de si ellos son o no son conocimiento verdaderamente con respecto al tema delimitado por el propio investigador. En efecto, cualquier tema es siempre, quiérase o no, un recorte limitado -en tales o cuales medidas - dentro de la infinidad de aspectos relacionados entre sí, tanto en exámenes sobre la realidad misma como en creaciones del propio pensamiento. La Teoría «estándar» de la Argumentación no procede, en tal sentido, de manera esencialmente distinta que cualquier teoría, sobre cualesquiera otros aspectos, acerca de lo que fuere. Ahora: ¿con eso basta para justificarla sin más, simplemente por constituir ella un «gusto» intelectual entre tantos?

Pues bien, lo que aquí estoy sometiendo a crítica no es el «gusto» intelectual por recortar así, esto es, lo de interesarse meramente por unas idealizaciones «estándar» como formas de argumentación jurídica, sino el hecho de no poner claramente sobre la mesa que ahí se trata justamente de eso: no dejar debidamente aclarado en tales estudios que, como suele advertirse en las películas, «cualquier semejanza con hechos o personas reales es una simple coincidencia...». La Teoría «estándar» de la Argumentación jurídica viene a ser algo así como una película de (ius)ciencia-ficción («cirugía estética») sobre el pensamiento de los juristas profesionales, pero se presenta —al menos implícitamente_ como si fuera un «documental» acerca de la vida real en los tribunales.

En efecto, difícilmente en los cursos especializados de «argumentación» para juristas, cuyas enseñanzas son por lo general afines a las idealizaciones ofrecidas por los estudios de orientación «estándar» acerca de ella, hemos de encontrarnos claramen-

enterado, ni ese autor ni ninguno de sus abundantes seguidores ha «chistado palabra» ni siquiera sobre las razones presentadas por los compatriotas suyos que le señalé en esos sitios.

73 C. COURTIS, en AA.VV. (C. COuRTIS, ed.), Observar la ley. Ensayos sobre metodología de la investigación jurídica, Madrid, 2006, 14 (vid. la cita en el Motto del presente estudio). Comentario sobre esa obra: 2007c. 
te subrayado (para descartar de antemano falsas ilusiones) con unas advertencias tan francas como éstas:

«Toda sentencia si bien representa una expresión del proceso mental de su autor, que precede al fallo formal, es apenas una pequeña muestra de ese proceso, en ocasiones tan exigua que resulta imposible evidenciar las verdaderas razones que llevaron al juzgador a decidir en un sentido y no en otro. Esa pequeña muestra del complicado y difícil proceso mental que conduce al juez a dictar una decisión, es lo que se estudia desde el punto de vista de la argumentación, ya que ella contiene todos los elementos que a ésta interesan, aun cuando, no pocas veces del resultado de la evaluación argumentativa que de ella se haga afloran las razones que el autor se guardó.

Desde luego que un estudio del fallo bajo el punto de vista de la argumentación puede conducirnos a encontrar indicios de que, en no pocos casos, las premisas que obran formalmente como sustento de la decisión no sirven más que para encubrir los motivos y las razones que reposan en la psiquis del juzgador y que, por alguna razón, éste no puede o no quiere ofrecer como legítimas en el plano formal de la sentencia. En otras ocasiones nos ofrece la prueba del desorden mental de quien produce la sentencia, pudiendo ser revelador de ignorancia o desconocimiento de la materia tratada, del expediente o de ambas cosas a la vez, con o $\sin$ razones ocultas» ${ }^{74}$.

Sí, apenas una «pequeña muestra»... Sólo que aun esa «pequeña muestra», cuando es tomada de la práctica jurídica (¡y sin disimulaciones!), suele diferir sensiblemente de las visiones idealizadas que al respecto nos presenta la ideología profesional sustentada por las teorizaciones «estándar» al respecto.

$$
* * *
$$

EN SÍNTESIS: La Teoría («estándar») de la Argumentación jurídica es engañadora, mas no simplemente por apartar la vista de los principales elementos prácticos efectivos que obran para tomar las decisiones judiciales (los «de tipo psicológico, sociológico, ideológico, etc.»), sino que, por encima de todo, no menos omisa es en su caracterización de esos razonamientos como tales. Ni siquiera de estos mismos da una cuenta acertada dicha Teoría, puesto que: a) prescinde de dirigir la atención hacia los tipos de «celadas» corrientes con que muy a menudo se configuran aun esos razonamientos en sí mismos; b) hace pasar, subrepticiamente, unos caracteres propios de argumentaciones ideales como si fueran también los dominantes en las argumentaciones jurídicas reales.

A semejantes teorizaciones les viene como anillo al dedo, mutatis mutandis, una observación general como la siguiente (sustitúyase, en la cita, «ciencia política» por «teoría de la argumentación»):

«Decía L. STRAuss de la "nueva" ciencia política, en conclusión, que "está tocando la lira, mientras Roma arde”. (...) Mas, a propósito del atenuante que irónicamente agregaba StRAuss, "la excusan dos hechos: no sabe que está tocando la lira y no sabe que Roma arde", bien pudo todavía puntualizarse que ella no sabe lo del incendio, precisamente porque su inteligencia está absorta con el instrumento, y muchas veces tanto que parece alienada en él» ${ }^{75}$.

${ }^{74}$ Febres Siso, loc. cit. (ref. supra, nota 69), 2 (negr. e.p.h.).

75 C. StRAsSER, La razón científica en política y sociología, Buenos Aires, 1977, 172. 


\section{EXCURSO: DISTINTAS FUNCIONES DISCURSIVAS DE LO «IDEAL» (PUEDE SERVIR PARA DELINEAR MODELOS YA SEA DE ENJUICIAMIENTOS, DE COMPARACIONES EMPÍRICO-CIENTÍFICAS O DE DISIMULACIONES IDEOLÓGICAS)}

Al efectuar un llamado a la realidad frente a idealizaciones como las de la teoría «estándar», o aun otras que no son propiamente «argumentativistas» (p. ej., RAWLS), se me ha replicado — si acaso alguien se digna hacerlo, aunque no en publicaciones- ${ }^{76}$ que renunciar a aquéllas significa quedarse simplemente en el culto al fait accompli. Dicen que es caer en el «reduccionismo» positivista ( $¡$ mala palabra!), por el cual la inteligencia queda encogida al papel de fijarse nada más en lo que ya es, convalidando así esa misma realidad; sería resignarse a ésta, sea cual fuere. Significa, aducen ellos, renunciar a considerar el papel de los ideales, quedar forzado a abstenerse de enjuiciar críticamente tal realidad. Pues bien, tales observaciones no contienen ni un ápice de verdad.

Ha sido aclarado en infinidad de ocasiones: una cosa significa el hacer ver que no constituye lo mismo un ideal («debe») que la propia realidad («es») a que ese ideal se refiere - otra, muy diferente, sería propugnar que cierto ideal no sea tomado en consideración para juzgar valorativamente y tal vez hasta tratar de introducir modificaciones en cierta realidad- . Lo primero, significa no confundir ideal con realidad lo segundo, sería creer ( ¡qué disparate!) que el pensamiento humano puede funcionar sin dejarse guiar mediante ideales, sean cuales sean. Por lo demás, hay «ideales» e «ideales»... No todos ellos obedecen a iguales características de pensamiento, ni guardan las mismas relaciones, ya sea de impulso o de freno, con respecto a unos u otros aspectos de la vida real $^{77}$. No es cuestión de impugnar todo ideal, como tampoco de encomiarlos in genere, sino saber apreciar para qué sirve en la realidad — pragmática lingüística— cada uno de ellos por su propia parte respectivamente.

Las objeciones que aquí he presentado frente a la teoría «estándar» de la argumentación, como asimismo las que en otros sitios he formulado contra la «Santa (charla-) Familia» en general (RAWLS, HABERMAS, DWORKIN, AlEXY y otros) ${ }^{78}$, no se refieren al mero hecho de que se propongan ideales. Me ocupo de la función real —ilusionismos, escapismo- que este orden de ideales — ¡no otros ideales! — cumplen como trabas para el conocimiento. Porque:

a) Semejantes ideales son presentados como si ellos, en sí mismos, guiaran efectivamente al pensamiento jurídico normal.

b) Tal indistinción, entre «debe» $\mathrm{y}$ «es», disimula cómo los juristas profesionales piensan y actúan realmente.

c) Esta disimulación específica aparta la atención de las dificultades vivientes en las comunicaciones y en general de cómo son las relaciones entre los seres huma-

${ }^{76}$ No conozco que existan objeciones publicadas. Eso sí, no se ve qué provecho puedan, aquellos colegas que saben de mis trabajos publicados, extraer de polemizar con lo señalado en éstos, dado que mis exámenes no comulgan con ninguna de las modas montadas sobre el viento a favor del efecto-Vicente, ni estoy afiliado a círculo alguno de los consabidos do ut des que señala GARCíA AMADO (infra, nota 79).

77 Infra, $\$ 10$.

${ }^{78}$ Cfr. 1998, 2001a o 2009a, 2007a, 2009b, 2010b (cap. V). 
nos comunes (gentes que, quiérase o no, acostumbran ser muy poco «racionales» o «razonables», de hecho), en lo cual los juristas están muy lejos de constituir una excepción.

d) Como consecuencia, semejante vis del pensamiento teorético aleja también de buscar soluciones realistas que permitan mejorar en algo —en función de ideales, claro está, pero los relativamente factibles en la práctica- ciertas deficiencias.

Por lo demás, ni siquiera niego que aun esos ideales profesorales puedan, y hasta me gustaría que lo consiguieran, desempeñar algún papel en la vida académica (si bien, en los hechos, tal papel es muchísimo menor de lo que se proclama) ${ }^{79}$. A lo que me enfrento es a las teorizaciones que sustentan el escapismo, pues ellas desvían la atención hacia unas imaginerías conducentes a hacer pensar que tales ideas tienen, o puedan llegar a tener, semejante papel también en la política y en el ejercicio habitual de la profesión jurídica. Las relaciones humanas no suelen moverse por el arte de hurgar en unas razones ideales. Esas relaciones responden a encontrados oleajes de intereses, pasiones e ideologías, también en las conductas discursivas que constituyen la especial esfera denominada Derecho (FREUD: «Así, pues, los argumentos lógicos serían impotentes contra los intereses afectivos, y por eso el luchar con razones - las cuales, según FALSTAFF, son tan comunes como las frambuesas- es tan estéril en el mundo de los intereses» ${ }^{80}$. El pecado original de la teoría de la argumentación con respecto al pensamiento jurídico es pasar por encima de tal comprobación básica, no obstante hallarse ésta tan al alcance de la mano.

$$
* * *
$$

Es capital no perder de vista unas diferencias esenciales en cuanto al posible papel de los ideales en el pensamiento. Se trata de las diferencias, que son fundamentales, entre cuatro grandes modelos de aproximación a las cuestiones sociales, sean o no sean éstas de orden específicamente jurídico.

i) Modelo de ideal valorativo: Es un proyecto, un propósito cuya realización se juzga deseable, y también bastante viable, con vistas a corregir tales o cuales aspectos de la realidad actual.

ii) Modelo como «tipo ideal» (según la categoría de pensamiento denominada así por M. WEBER): Se trata principalmente de un medio heurístico para poner cierto orden, de acuerdo con criterios de selectividad determinados por tales o cuales intereses de conocimiento, en la captación intelectual de determinados aspectos —así escogidos- acerca de realidades que son mucho más complejas. Entonces no se desconoce que la práctica difiere del modelo trazado. Las diferencias entre éste y ella pueden hasta ser muy amplias, inclusive insalvables, mas hay un interés en compararla con aquél justamente, sobre todo para juzgarla (¡crítica!).

79 De hecho, lo que en el establishment académico de la disciplina Teoría del Derecho predomina son: «... todos esos que parecen hábitos científicos y no suelen ser más que ritos gremiales..., toda la parafernalia de publicaciones, congresos, encuentros, reuniones, proyectos, conferencias, cursos, convenios..., heteróclito conjunto que en muchas ocasiones no encierra más cosa que la circularidad de un discurso vacío y la complicidad de colegas que en su relación se rigen más por el viejo principio de do ut des que por el más mínimo apego a la verdad o la decencia científica» (J. A. GARCíA AMADO, «Prólogo» en 2010b, 22).

80 S. FREud, El malestar en la cultura y otros ensayos (trad. R. Rey Ardid et al.), Madrid, 1970, 110. Vid. también: 2010b. 
iii) Modelo de tipo promedial: Este punto de vista, a diferencia del anterior, pretende corresponder a comprobaciones sobre cómo pasan las cosas habitualmente en la realidad misma. Mediante él se trata de registrar cómo suelen proceder de hecho, en la generalidad (o por lo menos en la mayoría) de los casos, los protagonistas reales — ¡no unos seres ideales! - de la actividad empírica de donde se considera inducido el modelo en cuestión.

iv) Modelo de idealización, que disimula («embellece») cómo son ciertas realidades sociales: Se presenta como si fuera ni más ni menos que la descripción de realidades efectivamente dadas, cuando lo cierto es que los discursos académicos concentrados en elucidar tales idealizaciones atienden poco o nada a cómo son los razonamientos utilizados en la práctica. Esas elucidaciones se ocupan de ciertos modelos i), pero que en ellas no se perciben como tales, sino que ahí son tratados como si correspondieran a modelos iii).

El primer modelo tiene su lugar propio en efectuar unos juicios de valor, sobre realidades sociales o sobre proyectos; lo cual es perfectamente legítimo siempre y cuando no por ello se confunda esos juicios con cómo son aquellas realidades en sí mismas. La segunda y la tercera clases de modelos pueden servir, eventualmente, como elementos integrantes de explicaciones empírico-científicas. Sobre los de la cuarta clase, en cambio, está vertebrado el campo propio de las disimulaciones ideológicas, ya sean más generales (señaladamente las doctrinas políticas) o más especiales (así las ideologías profesionales).

Estas cuatro formas guardan, como se ve, respectivamente relaciones muy distintas con la realidad. Ahora bien, en las «construcciones» a que se abocan los iusmetodólogos de la actual Teoría del Derecho, así nuestros «argumentativistas», allí los planos i) a iii) no se captan diferenciadamente entre sí. Probablemente sea ello la razón fundamental por la cual esos autores no caen en la cuenta de que sus laboriosas construcciones son a la vez tan «racionales» (o «razonables») como fantasiosas. De ahí que, a diferencia de «tipos ideales» como los señalados por WEBER, resulta que unas ideas como la «posición original» que postula RAWLS o el Hércules de DwORKIN o las construcciones de ALEXY o las axiomatizaciones de FERRAJOLI, por ejemplo, son tan desorientadoras con respecto a las prácticas de quienes protagonizan la actividad jurídica corriente; compárese tales construcciones con estudios realistas acerca del pensamiento judicial (p. ej., el implacable informe de LAUTMANN) ${ }^{81}$. En definitiva, tales ideas constituyen modelos del plano iv). Específicamente, son ideologías para legitimar ciertos renglones del discurso profesoral contemporizador con el establishment jurídico (si bien no hay por qué suponer que sea justamente esa la intención subjetiva de sus autores).

EN SíNTESIS: La Teoría «estándar» de la Argumentación es esencialmente engañadora, pero no precisamente porque acaso ella proponga cierto ideal que sea presentado como tal e incluido en el seno de unos razonamientos jurídicos como tal, sino justamente por disimular que ante todo y sobre todo es tal. En efecto, dicha teoría se halla asentada sobre los siguientes vicios de enfoque básicos:

${ }^{81}$ Op. cit. (ref. supra, nota 61). 
a) Ofrece una perspectiva que es principalmente axiológica [modelo i)], pero de modo implícito desliza la presuposición de que eso es asimismo una descripción empírico-promedial [modelo iii)], lo cual constituye una gruesa exageración.

b) Tampoco se trata de algo así como un «tipo ideal» en el sentido técnico de M. WeBER [modelo ii)]. Si lo fuera, ahí éste sería sobre todo descriptivo-crítico, pues mediante él no habría más remedio que comprobar cuánto los razonamientos jurídicos reales se apartan habitualmente de tal racionalidad o razonabilidad típíco-ideal. Por el contrario, los constructos argumentativistas sirven sobre todo para desviar la vista de esa distancia fundamental [Síndrome, etc.], que así queda disimulada por concentrarse la atención sobre unas «cirugías estéticas» (COURTIS) ${ }^{82}$ al respecto.

c) En virtud de la confusión a) y del encubrimiento b), la idealización «argumentativista» sobre los razonamientos jurídicos constituye sobre todo una presentación escapista-encubridora -ideología gremial - frente a cómo funcionan esos razonamientos en la práctica de los tribunales y en los discursos «técnicos» (dogmática) de su doctrina profesional en general.

\section{[IV]}

\section{CONCLUSIONES FUNDAMENTALES}

\section{STORYTELLING COMO RESULTADO: LA TEORÍA «ESTÁNDAR» DE LA ARGUMENTACIÓN JURÍDICA ES UNA IDEOLOGÍA PROFESIONAL ( «CIRUGÍA ESTÉTICA»)}

En virtud de todo lo que he venido señalando, resulta que la Teoría «estándar» de la Argumentación se constituye en una más dentro del amplio surtido de storytellings que componen el pensamiento sobre las dinámicas de lo social. En efecto:

«... según nos cuenta SALMON, mediante el storytelling se intenta suplir nuestras pérdidas cotidianas con buenas historias. La gente se miente a sí misma con sus propias historias. Una historia que procura una explicación tranquilizadora de los acontecimientos también puede engañar al eliminar las contradicciones y las complicaciones. El storytelling, entonces, se erige en un arma de distracción masiva que no admite el estatus de ficción [acerca de sí misma]: “... cuando una persona es lo bastante afortunada para vivir dentro de una historia, para habitar un mundo imaginario, las penas de este mundo desaparecen. Mientras la historia sigue su curso, la realidad deja de existir" (P. AUSTER). "Es la fe la que hace mover montañas y no los hechos. La fe necesita una historia para sostenerla —una historia con significado que sea creíble y que dé $f e$ en usted-” (A. SimMONS)» ${ }^{83}$.

La story específica narrada por dicha Teoría consiste en «suplir» las prácticas discursivas reales de los operadores jurídicos profesionales (sus «pérdidas cotidianas») con unos maquillamientos racionalistas, bajo los cuales «las penas (Síndrome y demás) de este mundo (jurídico) desaparecen», sustituidas por esas «buenas historias» desempeñadas por unos operadores de vis «hercúleamente» ${ }^{84}$ iusrraciocinante.

\footnotetext{
82 Supra, nota 73.

83 M. RoIG, «Prólogo», en SALmon, op. cit. (ref. supra, núm. 2), 2008, 11-25: 13 y 19 (curs. e.p.h.).

84 Valga la imagen popularizada por el menos ilustrado de los autores de Teoría del Derecho muy citados (cfr. 2001a o 2009a).
} 
El pensamiento jurídico es mostrado como consistente en tales o cuales «novelas de conceptos» ${ }^{85}$ racio-argumentativistas. Por apartar la vista de las prácticas jurídicas efectivas, presentando a cambio como una «cirugía estética» ${ }^{86}$ al respecto, bien puede decirse que tales teorizaciones constituyen expedientes de neto contenido escapista frente a la «vida» del Derecho. Son teorías que postulan unas formas de argumentar ideales, dan poco o nada cuenta acerca de cómo son los razonamientos jurídicos profesionales reales. Eso sí, ¡con la pretensión de hacer pasar las primeras por los segundos!

\section{Complemento: Tres condiciones minimas de practicabilidad (SALAS).}

«Es atinado poner el énfasis en el papel argumentativo de la labor jurídica. También es correcto enfatizar el hecho de que en esa labor argumentativa el pensamiento tópico, dialéctico o incluso retórico, juegan un papel importante. En esto, autores como PERELMAN, TOULmin, ALEXY o ATIENZA tienen su razón. Sin embargo, la debilidad principal es que la teoría de la argumentación, al concentrarse en el plano metateórico, asume que los interlocutores jurídicos (es decir, el "auditorio") se comportarán, en su praxis vital y profesional, según los parámetros allí recogidos. Con otras palabras, para que los distintos elementos - racionales o razonabilistas - de una teoría de la argumentación sean útiles se requieren, al menos, tres condiciones mínimas: primera, que los interlocutores (i. e., los operadores del Derecho a quienes se dirige la teoría) conozcan, con algún grado de detalle, los elementos metodológicos propuestos por esa teoría; segunda, una cierta "sensibilidad" cognitiva para dejarse convencer (ya no sólo persuadir) por los argumentos; y, tercera, implementar en la práctica de su ejercicio profesional y vital esos argumentos.

En lo personal, tengo mis dudas de si en el mundo jurídico, específicamente en la praxis burocrática del universo judicial, se cumplen esas tres condiciones; si bien hay que reconocer que puede darse aisladamente alguna de ellas. Por ejemplo, puede ser que un juez conozca con mucho detalle intelectual las formalizaciones de ALEXY, pero entonces cabría cuestionarse si estas formalizaciones se utilizan en su labor profesional y, sobre todo, cómo es que se utilizan: ¿como legitimación de lo que se dice, como «adorno» de erudición o como elemento realmente decisivo?». (M. SALAS, «Debate sobre la utilidad de la Metodología Jurídica. Una reconstrucción crítica de las actuales corrientes metodológicas en la teoría del Derecho», Isonomía, núm. 27, 2007, 111-142).

\section{EPÍLOGO: ¿ES DABLE TENER UNA TEORÍA REALISTA DE LA ARGUMENTACIÓN JURÍDICA?}

Ya lo dije, no es cuestión de negar que los discursos jurídicos están conformados con base en argumentaciones. Asimismo es verdad que las «gramáticas» de esos discursos - es decir, sus pautas propias de inferencia - difieren sustancialmente de las utilizadas para los razonamientos en las ciencias de la naturaleza y los de la lógica formal; pero difieren también, no menos, de las metodologías aplicadas para convalidar los enunciados en las ciencias sociales empíricas.

Los argumentos que utilizan los juristas profesionales para llevar a cabo su actividad como tales, según cómo ello funcione en la cabezas de estos mismos y qué consecuencias prácticas se sigan de ahí, son un elemento importante de la realidad

\footnotetext{
85 Supra, nota 4.

${ }^{86}$ Ref. supra, nota 73.
} 
jurídica misma; incluso lo es la presencia de unos ideales, allí, cuando éstos funcionan realmente - en alguna medida, mayor o menor- como impulsos para las conductas efectivas de quienes se dejen guiar por ellos. Ninguna teoría plenamente realista acerca del Derecho puede desconocer tales hechos, la decisiva función psicológica de unos ideales. Pero el realista no exagera los alcances propios de estos hechos, cuando son tales. Sabe distinguir entre «ideales» e «ideales» ${ }^{87}$, según sus respectivos efectos de hecho: pragmática jurídica. Esto es, según cómo esos ideales repercutan — ¡o no! — en las prácticas concretas de los operadores jurídicos encargados de ponerlos en acción (real o supuestamente) y en la vida misma de los destinatarios que reciben las consecuencias producidas — ¡o no! - por los discursos de esos operadores. Todo examen realista acerca del Derecho se cuidará muy bien en evitar cualquier suerte de espejismos al respecto. Sabrá eludir, pues, la tentación de caer en esos ilusionismos teoréticos que llevan a tomar, así sea tácitamente, unas argumentaciones jurídicas ideales —-teoría «estándar»- como si fueran aproximadamente lo mismo que las argumentaciones jurídicas efectivas.

Los análisis propios de una teoría realista sobre la argumentación de los juristas se inspirarán sobre todo en la primera etapa de PERELMAN (Traité...) y en aprehender los razonamientos jurídicos como una «tópica» ${ }^{88}$. En cambio, sabrán tomar «con pinzas» lo del PERELMAN posterior (supra, $\mathbb{2}$ ), como tampoco caerán para nada en la tentación de ponerse a pergeñar visiones idealizadas como hacen ALEXY y Cía. ${ }^{89}$. En una palabra, los realistas considerarán las argumentaciones jurídicas tal como son en la práctica profesional del Derecho. Debiera servir como inspiración el ejemplo excepcional, tal vez único, que ofrecen los análisis de W. SCHEUERLE (1958-1972) ${ }^{90}$, aunque ahí no se recurre al letrero «teoría de la argumentación».

Si bien los exámenes realistas reconocen qué importancia efectiva tienen respectivamente distintas argumentaciones jurídicas, empero ellos, a diferencia de las teorías idealistas sobre la materia, no pueden consentir en disimular:

a) Que dichas argumentaciones suelen elaborarse con base en sustanciales vicios de razonamiento (Síndrome), o al menos ellas están en buena parte entrelazadas con tales elementos de no-razonabilidad (sean unos u otros).

b) Que los argumentos en cuestión se hacen entrar en juego subordinados a, o al menos quedando limitados o influenciados por, toda suerte de factores materiales

87 Supra, $\mathbb{\$} 9$.

88 Cfr. 2007 b (sec. H.IV. 3) y 1977.

89 Vid. 1998.

90 He aquí una lista de estudios (insustituibles) pertenecientes a dicho autor: «Beiträge zum Problem der Trennung von Tat- und Rechtsfrage» («Contribuciones al problema de la separación entre la cuestión de hecho y la de Derecho»), Archiv für die civilistische Praxis (AcP), 157, 1958, 1-85; «Das Wesen des Wesens. Studien über das sogenannte Wesensargument im juristischen Begründen» («La esencia de la esencia. Estudios sobre el llamado argumento de la esencia en la fundamentación jurídica»), AcP, 163, 1964, 429-471; «Die Logik der Logik. Studien über logische Argumente und Methodenehrlichkeit im juristischen Begründen» («La lógica de la lógica. Estudios sobre argumentos lógicos y la honradez metodológica en la fundamentación jurídica»); Zeitschrift für Zivilprozeß (ZZP), 78, 1965, 32-76; «Finale Subsumtionen - Studien über Tricks und Schleichwege in der Rechtsanwendung» («Subsunciones finales - Estudios sobre ardides y vías de disimulación en la aplicación del Derecho»), AcP, 167, 1967, 305-349; «Juristische Evidenzen» («Evidencias jurídicas»), ZZP, 84, 1971, 241 y ss.; «Formalismusargumente» («Argumentos formalistas»), AcP, 172, 1972, 397 y ss. Y vid. además el libro de dicho autor: Vierzebn Tugenden für vorzitzender Richter (Catorce virtudes para Presidentes de Tribunales), Berlin, 1983. 
(condiciones de trabajo, presiones sociales, etc.) y de pre-juicios imperantes en el conocimiento vulgar [ideologías, estereotipos, Alltagstheorien (teorías cotidianas) ${ }^{91}$ en general] — «... una mezcolanza indisoluble de...» (infra)—.

c) Que los juristas no son unos meros raciocinadores, como tampoco lo son los seres humanos en general, ni la tradicional formación universitaria de aquéllos incluye el aprendizaje de ciertos conocimientos que son absolutamente básicos para el pensamiento racional en general (si aquéllos los poseyeran, no serían tan fácilmente víctimas del Síndrome).

d) Que la práctica judicial y administrativa está sometida a múltiples entrabamientos y entorpecimientos de orden esencialmente burocrático, los cuales muy a menudo resultan ser mucho más decisivos que cuanto eventualmente pueda producirse en el nivel de los razonamientos jurídicos propiamente dichos (cualesquiera sean).

¿Es posible una teoría realista de las argumentaciones jurídicas? ¡Claro que sí! Tal aproximación no podrá menos que tomar como eje de consideración básico, no la «construcción» de unos razonamientos ideales, sino el hecho de que el pensamiento jurídico profesional ha sido, es y siempre será (¡quiérase o no!):

«... una mezcolanza indisoluble de elementos teoréticos y prácticos, cognoscitivos y creativos, reproductivos y productivos, científicos y supracientíficos, objetivos y subjetivos» (RADBRUCH) ${ }^{92}$.

No me canso de hacer recordar tal caracterización, insuperable. Toda vez que el teórico del Derecho no remonte vuelo hacia unos universos de celestialidades jurídicas, en donde esa mezcolanza deje de ser tal para dar lugar (supuestamente) a ciertas «racionalidades» o «razonabilidades» jurídicas discernibles en una burbuja intelectual propia, lo interesante no podrá ser ponerse a «construir» semejantes universos, cuya principal realidad es que tienen usos en unos entretenimientos del pensamiento profesoral.

Dado que los juristas a menudo creen en sus propias argumentaciones y éstas efectivamente juegan un papel dentro de aquella gran «mezcolanza», no se ve por qué los exámenes realistas con respecto a pensamiento jurídico habrían de prescindir de aquilatar dicho papel. Pero se fijarán sobre todo, eso sí, en qué medida y cómo ellas cumplan tal papel en la propia práctica jurídica. De ahí que, al fin de cuentas, la condición básica de toda teoría realista sobre las maneras de argumentar de los juristas es que ella, a diferencia de la amplia gama de los estudios idealistas al respecto (i.e., no sólo los de enfoques argumentativistas), tendrá necesidad de poner el acento en todo aquello, justamente, que la teoría «estándar» de la argumentación jurídica saca afuera del tapete al ocuparse de la materia ${ }^{93}$.

91 Cfr. 2006a, sec. A, Tesis 5.

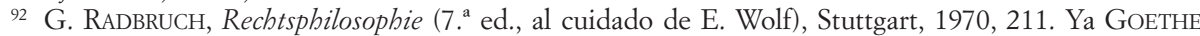
había anotado que: «Una ciencia es, como cualquier institución y organización humanas, una colosal ensambladura (ungeheure Kontignation) de lo cierto y lo falso, lo voluntario y lo necesario, lo sano y lo enfermizo» (Tag und Jabres-Hefte 1811).

93 Por ejemplo: un intento en tal sentido, precisamente el de «poner el acento en todo aquello», es la finalidad principal de mi Metodología jurídica irreverente (2006a). 


\section{TRABAJOS COMPLEMENTARIOS DEL AUTOR *}

— 1973: «Sur une "méthodologie" de l'interprétation juridique», Archives de Philosophie du Droit, XVIII, 371-383.

— 1977: «Rationalität der Autoritäten oder Autorität der Rationalität?» («¿Racionalidad de las autoridades o autoridad de la racionalidad?»), Rechtstheorie, 8, 145-163.

— 1978: «Hermeneutik contra Rechtswissenchaft» («Hermenéutica contra ciencia jurídica»), Archiv für Rechts- und Sozialphilosopbie, vol. LXIV, 163-181.

- 1980: «Presentación», en J. E. Romero PÉrez, La Sociología del Derecho en Max Weber (2. ${ }^{a}$ ed), i-xxxiv; San José, Oficina de Publicaciones de la Universidad de Costa Rica.

- 1982: Nota sobre «Gadamer: Verdad y Método», Revista de Filosofía de la Universidad de Costa Rica, núm. 51, junio, 96-99.

- 1988: «Rationalité», en A.-J. ARNAUD (ed.), Dictionnaire Encyclopédique de Théorie et de Sociologie du Droit, Paris-Brussels, 337-340.

- 1990: «Racionalidad y método para el Derecho: ¿es eso posible?», Doxa, núms. 7 y 8 , respectivamente 169-247 y 241-270. Una versión corregida y algo ampliada apareció en Revista de Ciencias Jurídicas (Universidad de Costa Rica), núms. 66 (mayo-agosto 1990) y 67 (septiembre-diciembre 1990), respectivamente 67-134 y 169-244; de esta versión hubo también un pequeño tiraje independiente en forma de libro.

— 1993: «Kirchmann sabía menos... ipero vio mejor! Vigencia de un antiguo diagnóstico, más algunas observaciones (que no son simpáticas) sobre la actual Teoría del Derecho»; Doxa, núm. 14, 269-317 (con unas cuantas erratas). Versión revisada: en AA.VV. (J. F. PALOMINO MANCHEgO, dir.), 1999: Discusión sobre el carácter anticientífico del Derecho (De Kirchmann a la discusión epistemológica actual), Lima, 47-107. Versión definitiva: 2011a, cap. II.

- 1995: «Sobre el Derecho como "técnica” o "tecnología”. Apostillas a una polémica sobre las posibilidades del discurso jurídico»; Doxa, t. 17-18, 491-498. También en AA.VV., 1999 (ref. supra, 1993), 107-116.

- 1996a/2003: «Lógica formal y Derecho»; Enciclopedia Jurídica Ameba, apéndice VII, 625632, Buenos Aires, 1996. Una versión revisada de este estudio pasa a ser el cap. VIII de 2003 (versión abreviada: cap. IV.1 de 2011ª).

- 1996b: «Standortbestimmung zeitgenössischer Rechtstheorie - Rawls, Dworkin, Habermas und andere Mitglieder der "Heiligen (Rede-)Familia"» («Ubicación de la Teoría del Derecho contemporánea - Rawls, Dworkin, Habermas y otros miembros de la "Santa (charla-)Familia”»), System der Rechte, demokratischer Rechtsstaat und Diskurstheorie nach Jürgen Habermas, HABERMAS-SONDERHEFT (Rechtstheorie, vol. 27, cuaderno 3, 1996), 277-327, Berlin, Duncker \& Humblot, publ. 1998. Título original de dicho estudio: «Zum astronautischen Standort der heutigen Rechtstheorie. Über Rawls, Habermas, Alexy und andere: Gegenwärtige Arten des akademischen Wunschdenkens in einer modernen "Heiligen (Rede-)Familia"» [«Sobre el astronáutico emplazamiento de la Teoría del Derecho contemporánea. Acerca de Rawls, Habermas, Alexy y otros: formas actuales del wishful thinking académico en una moderna "Santa (charla-) Familia" »]. Este estudio se halla traducido (por partes) en español,

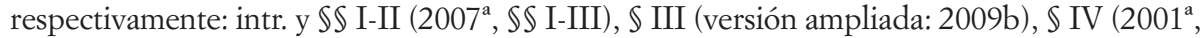
$\$ \$ 4-8), \mathbb{V}(1997,116-125), \mathbb{V I}(1998$ — revisado y ampliado: 2011a, cap. VI—).

- 1996c: «Una discusión : ¿Quiénes son los "irracionalistas” en la Teoría del Derecho? (Por qué algunos no confiamos en que sean tan "racionales", ni "razonables", los enfoques hoy

* Nota: La referencia a estos estudios en notas subpaginales del presente artículo se efectúa indicando simplemente el respectivo año de publicación. 
dominantes en esa Teoría)», Doxa, núm. 19, 385-402. Versión ampliada en P. MANCHEGO (op. cit.), 271-315. Versión definitiva: cap. III de 2011a.

— 1998: «Teorización constructivista como "forma de vida" (Sobre "formas y reglas" del discurso jurídico en los tribunales inexistentes)». Doxa, núm. 21, vol. I, 147-170. Pasa a formar parte, en versión revisada y ampliada, de $2011^{a}$, cap. VI.

- 1999: «Precomprensiones, racionalidad y métodos, en las resoluciones judiciales», Doxa, núm. 22, 49-78.

— 2000: «Semiótica ilusionista y semiótica desencantadora. Mitomanías de la Razón "constructivista": ¿racionalidad de los juristas o racionalidad de los iusemióticos?», Doxa, núm. 23, 561-596. Texto revisado: 2003c, Anexo.

— 2001a: «Rehabilitación del no-saber en la actual Teoría del Derecho: El bluff Dworkin (Retorno al realismo ingenuo y apogeo del efecto-Vicente, lanzados por una reencarnación más del Prof. Beale)», Doxa, núm. 24, 165-201. Versión completa (mucho más amplia que la publicada en Doxa): 2009a.

- 2001b: «Normativismo y realismo como opciones del juez (de la Razón práctica amputada a la racionalidad jurídica integral)», en J. M. DELGADO OCANDO y L. I. ZERPA (coords.), Curso de Capacitación Judicial sobre Razonamiento Judicial y Argumentación Jurídica, Tribunal Supremo de Justicia (Serie Eventos núm. 3), Caracas, 39-161.

— 2002: «Metodología realista-crítica y ética del razonamiento judicial (Realismo jurídico como alternativa práctica al discurso normativista de los jueces)», Doxa, núm. 25, 503-531. Los contenidos de este estudio pasaron luego, en presentación corregida y ampliada, a formar parte de $2006^{\mathrm{a}}$, secs. C.II-III y D.5.

- 2003: El espejismo de la interpretación literal. Encrucijadas del lenguaje jurídico, t. I y II, San José, Escuela Judicial de la Corte Suprema de Justicia de Costa Rica, Editorial Vlamarán, xii-207 + xv-335 pp.

- 2004: «Alcance heurístico del modelo "Autoridades" para examinar las argumentaciones de los juristas, y comparación de ese modelo con los enfoques "sistémicos" ("razonabilistas", etc.) en la actual Teoría del Derecho», en R. ZuLUAGA GIL (ed. y comp.), Interpretar y argumentar. Nuevas perspectivas para el Derecho, Medellín, Pontificia Universidad Javeriana Cali, 81-122.

- 2006a: Metodología jurídica irreverente. Elementos de profilaxis para encarar los discursos jurídicos terrenales; Universidad Carlos III de Madrid-Instituto de Derechos Humanos «Bartolomé de Las Casas» (col. Derechos Humanos y Filosofía del Derecho), Dykinson, Madrid, 442 pp. Versión muy ampliamente reelaborada: 2011 b.

- 2006b: «¿Puede el jurista discurrir como un científico social? (Posibilidades e imposibilidades del Derecho como "ciencia” social)», Revista de Ciencias Sociales (UCR), núms. 113114 (2006.III-IV), 37-54 [pdf: http://redalyc.uaemex.mx].

- 2007a: «Contra la "Santa (charla-)Familia". Anclajes básicos de la vocación astronáutica promovida por Rawls, Habermas y otros apóstoles del wishful thinking académico»; Doxa, núm. 30, 491-524.

- 2007b: Axiología jurídica fundamental. Bases de valoración en el discurso jurídico (Materiales para discernir en forma analítico-realista las claves retóricas de esos discursos), San José, C. R., Editorial de la Universidad de Costa Rica, Ciudad Universitaria Rodrigo Facio (ed. corr. y ampl. —1. ${ }^{a}$ ed. 2004—), xxi-411 (obtenible en: http://www.libreriaucr.com/catalogo/).

- 2007c: «Sobre Observar la ley. Ensayos sobre metodología de la investigación jurídica de Christian Courtis (ed.)», Isonomía, núm. 27, 205-213.

- 2009a: «El bluff Dworkin. Su rehabilitación del no-saber en la actual Teoría del Derecho»; en Criterio Jurídico, vol. 9, núm. 1 (1. ${ }^{\text {er }}$ semestre), 155-258 (pdf: http://criteriojuridico.puj. edu.co). 
- 2009b: «Rawls: El extraterrestre raciocinante. Teoría social en tanto que mero divertimento discursivo (Sobre la neoescolástica social de J. Rawls como paradigma de teorización alienada)», en Revista Telemática de Filosofía del Derecho, núm. 12, 223-267 (pdf: http://www. filosofiayderecho.com/rtfd). Pasa a formar parte, con leves diferencias, de 2010, caps. I.1 y V.2-5.

- 2010a: Los juicios de valor. Elementos básicos de Axiología General (2. ${ }^{a}$ ed.). Epistemología del discurso valorativo práctico (Materiales para discernir condiciones de racionalidad en esos discursos), San José, C. R., UCR, Ciudad Universitaria Rodrigo Facio, xxxvii-449 pp. (obtenible en http://www.libreriaucr.com/catalogo/). Es la edición revisada y ampliada de la obra publicada anteriormente, 2004 y 2008, bajo el título principal: Elementos básicos de Axiología General.

- 2010b: Entre tecnócratas y «wishful thinkers». La concepción misionera de las ciencias sociales (pról. J. A. GARCía AmADO), Granada, Comares, 370 pp.

- 2011a: La ciencia de los juristas: ¿qué «ciencia»?. De la ciencia jurídica normal a la ciencia jurídica exquisita, San José (C. R.), Editorial Jurídica Continental (en prensa) (será obtenible en: http://www.libreriaucr.com/catalogo/).

- 2011b: Metodología (realista) del Derecho. Claves para el razonamiento jurídico de visión social práctica (versión ampliamente reelaborada, y muy aumentada, de 2006a), San José (C. R.), Instituto de Investigaciones Jurídicas-Universidad de Costa Rica (en prensa) (será obtenible en: http://www.libreriaucr.com/catalogo/). 